INSTITUTO DE PESQUISAS ENERGÉTICAS E NUCLEARES

AUTARQUIA ASSOCIADA À UNIVERSIDADE DE SÃO PAULO

\title{
OBTENÇÃO E CARACTERIZAÇÃO DE REVESTIMENTOS COMPOSTOS DE MULTICAMADAS $\mathrm{TiO}_{2} / \mathrm{TIN}$
}

\section{ANDRÉ GONÇALVES}

\begin{abstract}
Dissertação apresentada como parte dos requisitos para obtenção do Grau de Mestre em Ciências na Área de Tecnologia Nuclear - Materiais.
\end{abstract}

Orientadora:

Profa. Dra. Marina Fuser Pillis 


\section{AGRADECIMENTOS}

Agradeço a Dra. Marina Fuser Pillis, minha orientadora, pela orientação segura e confiança.

Agradeço ao professor Marcelo Carreño, do laboratório de microeletrônica da EPUSP, pela contribuição neste trabalho.

Agradeço ao professor Zoroastro de Miranda Boari, pelo incentivo e apoio ao desenvolvimento científico.

À minha família e amigos pelo incentivo permanente e torcida pelo sucesso na conclusão dessa dissertação.

A todos os professores do programa que não mediram esforços para transmitir e ensinar os seus conhecimentos ao longo desses anos de jornada. Aos assistentes do programa que sempre se mostraram presentes e prestativos, na divulgação de informações, meu reconhecimento e agradecimento.

Aos meus colegas do IPEN que, de alguma forma, contribuíram para a realização deste trabalho.

Ao Instituto de Pesquisas Energéticas e Nucleares (IPEN) que introduziu este programa de pós-graduação, inovando no ensino acadêmico. 


\title{
OBTENÇÃO E CARACTERIZAÇÃO DE REVESTIMENTOS COMPOSTOS DE MULTICAMADAS $\mathrm{TiO}_{2} / \mathrm{TIN}$
}

\author{
ANDRÉ GONÇALVES
}

RESUMO

A nanociência emergiu nos últimos anos como uma das áreas mais importantes para os futuros desenvolvimentos tecnológicos, especialmente na área de dispositivos eletrônicos. A nanotecnologia tem um caráter primordialmente interdisciplinar, que engloba conhecimentos de física, química, engenharias e biologia. Essa tecnologia está sendo usada da fabricação de microprocessadores, bombas dosadoras de fármacos e revestimentos em materiais, entre outras aplicações.

Revestimentos nanocristalinos vêm sendo obtidos por meio da técnica MOCVD (deposição química de organometálicos em fase vapor), e tem proporcionado a obtenção de filmes de melhor qualidade que os obtidos por CVD convencional ou por métodos físicos. Além disso, a técnica MOCVD apresenta-se como uma alternativa competitiva porque é relativamente barata e mais fácil de ser implantada, em relação aos métodos de deposição física.

Neste trabalho foram obtidos revestimentos compostos por multicamadas de $\mathrm{TiO}_{2} / \mathrm{TiN}$. Durante o experimento, a abertura e o fechamento das válvulas de admissão dos gases exige do operador habilidade manual para acionar a válvula e controlar o tempo de deposição, o que gera possibilidade de erros, implicando diretamente na espessura de cada camada. Assim, a necessidade de diminuir a influência do operador e poder utilizar intervalos de tempo menores que um minuto para os crescimentos, gerou a oportunidade de criar um programa de computador para gerenciar todo o sistema. Tal programa foi desenvolvido utilizando-se o conceito de "Máquina de Estados" para o controle de processo e simulação "Hardware in the loop". 


\title{
OBTENTION AND CHARACTERIZATION OF $\mathrm{TiO}_{2} /$ TIN MULTILAYERS COATINGS
}

\author{
ANDRÉ GONÇALVES
}

ABSTRACT

Nanoscience has emerged in recent years as one of the most important areas for future technological developments, especially in the area of electronic devices. Nanotechnology has an interdisciplinary character wich includes knowledge from physics, chemistry, engineering, and biology. This technology is being used in the manufacture of microprocessors, pumps for dose of medicine, and coating materials, among others.

The MOCVD technique has been used recently to obtain nanocristalline coatings, and provide films of better quality than those obtained by conventional CVD or physical methods. Furthermore, the MOCVD technique presents itself as a competitive alternative because it is relatively inexpensive and easy to deploy compared to physical deposition methods.

In this work multilayer coatings of $\mathrm{TiO}_{2} / \mathrm{TiN}$ were produced. During the experiment, the opening and closing of the valves of gases admission, requires from the operator manual ability to trigger the valve and controlling the deposition time, which creates the possibility of errors, leading directly into the thickness of each layer. Thus, the need of reducing the influence of the operator, and the possibility of using time intervals of less than a minute in the growths, created the opportunity to develop a computer program to manage the whole system. The software was developed using the "State machine" concept for the process control and Hardware in the loop simulation. 


\section{SUMÁRIO}

AGRADECIMENTOS ............................................................................. ii

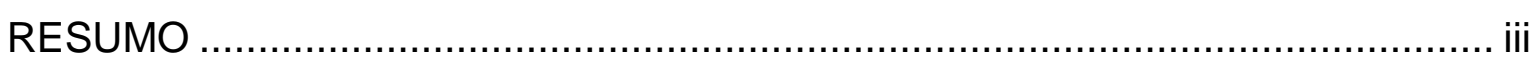

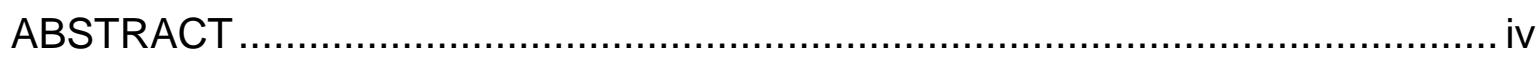

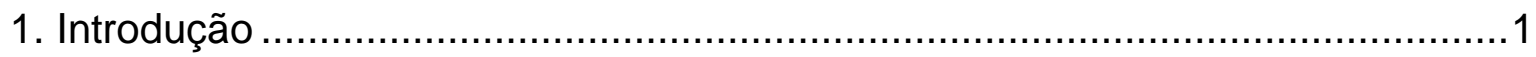

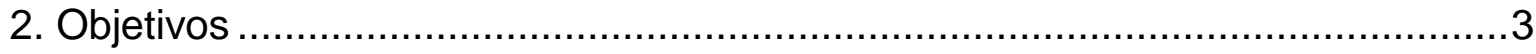

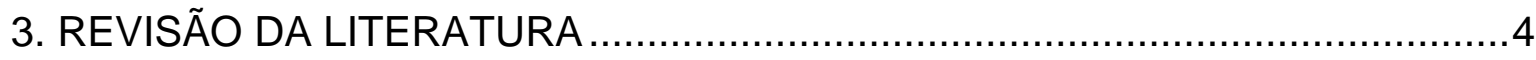

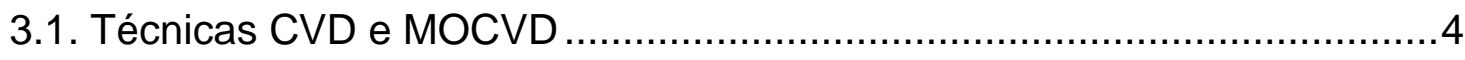

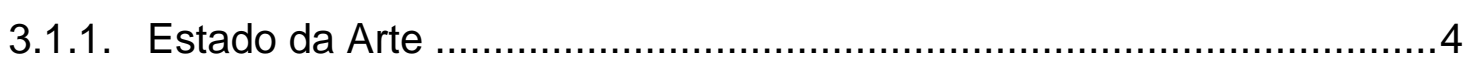

3.1.2. Deposição química em fase vapor - O processo CVD ......................5

3.1.3. Deposição química de organometálicos em fase vapor (MOCVD) .......5

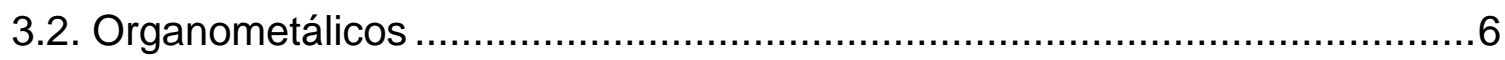

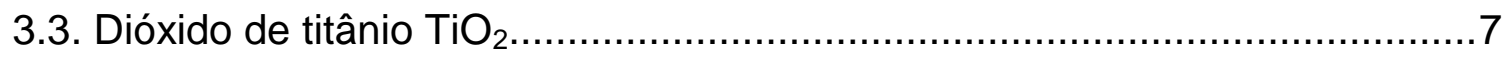

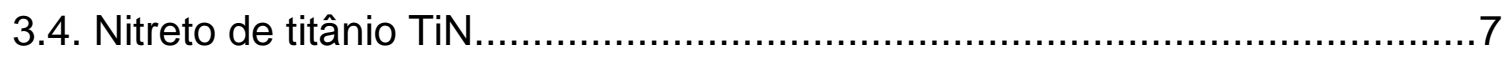

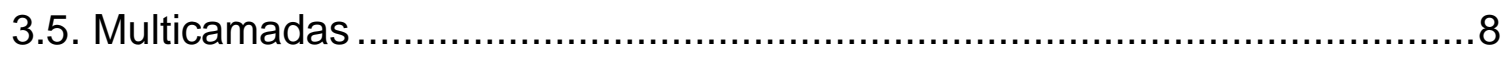

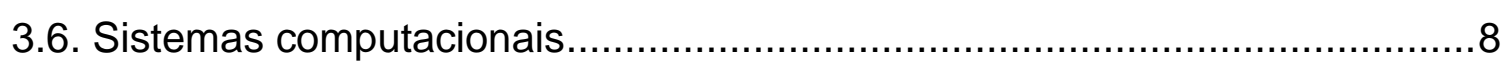

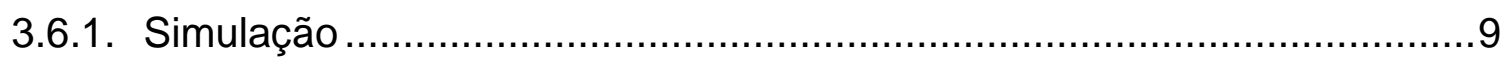

3.6.2. "Hardware in the loop (HIL)" ..................................................... 10

3.6.3. Simulação com "Hardware in the Loop" ....................................... 12

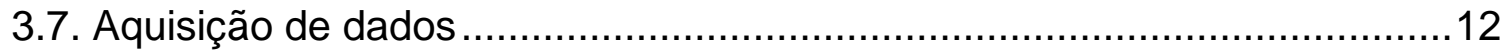

3.8. Transdutores e Condicionadores de Sinal ........................................... 14

3.9. Máquina de Estados .............................................................. 14

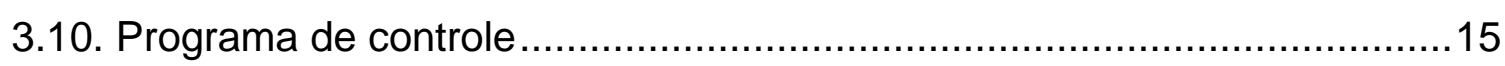

4. Materiais e Métodos ......................................................................... 16

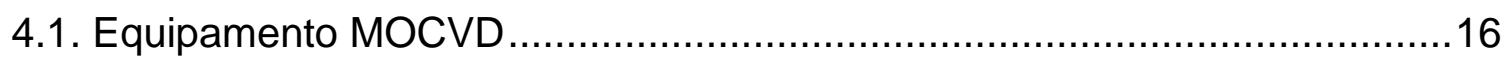

4.1.1 Parâmetros de Deposição ........................................................ 19

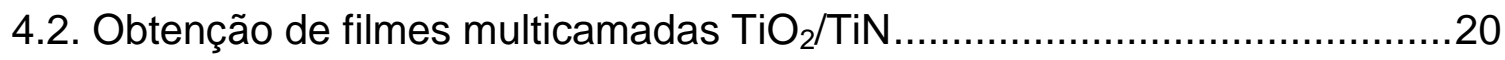

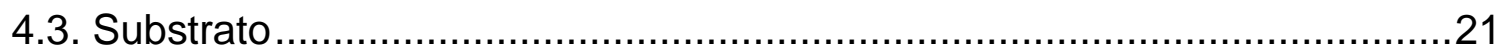

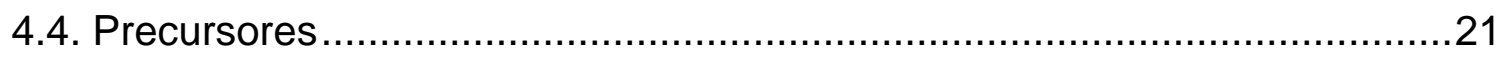

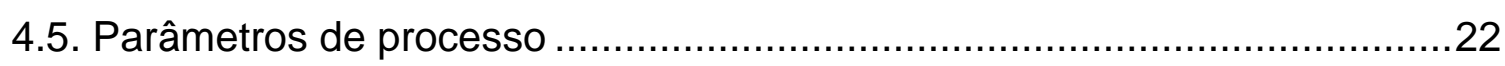

4.6. Caracterização das amostras......................................................... 23 
4.6.1. Caracterização por Microscopia eletrônica de varredura com emissão de

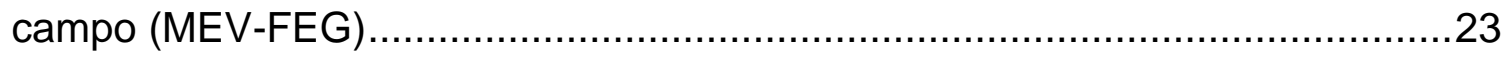

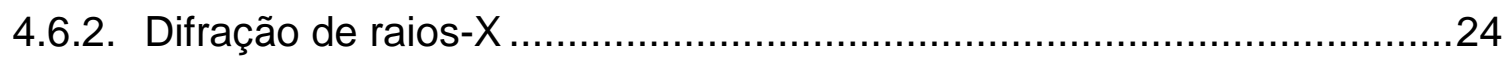

4.7. Controle de abertura e fechamento das válvulas ......................................24

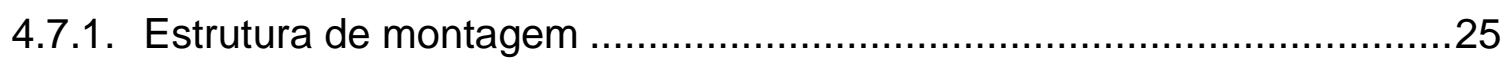

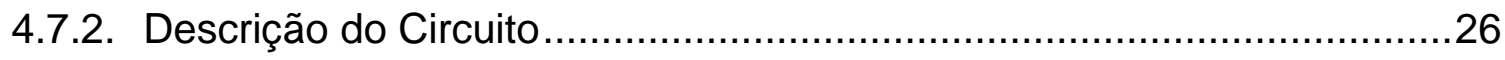

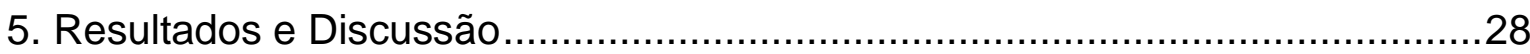

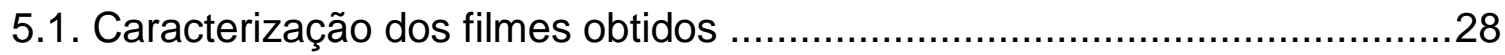

5.2. Montagem do circuito e simulação do sistema...............................................

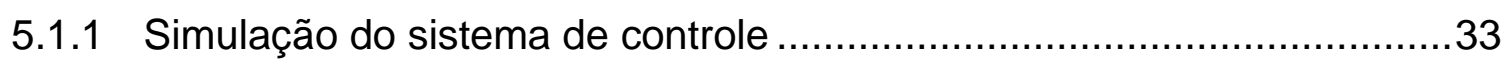

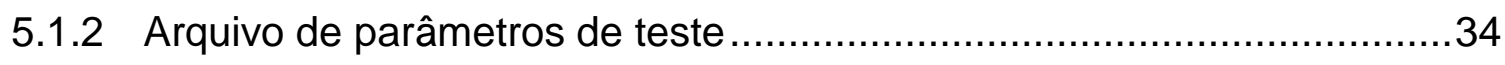

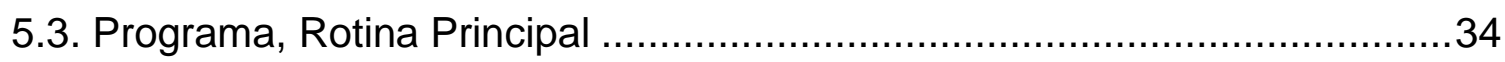

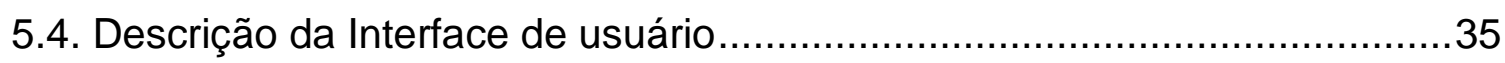

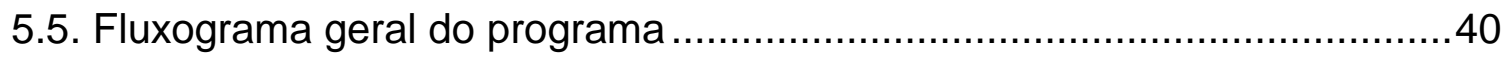

5.5.1. Fluxograma das chamada de funções do programa.............................42

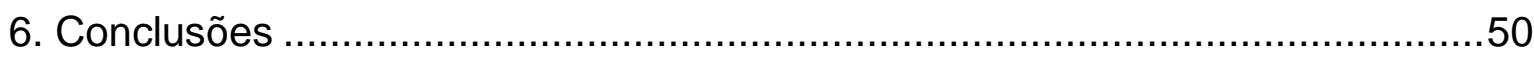

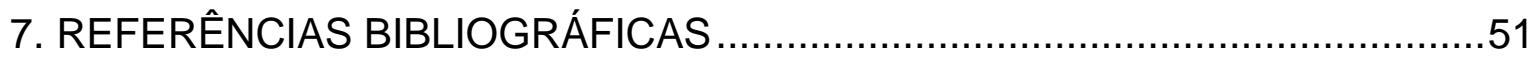

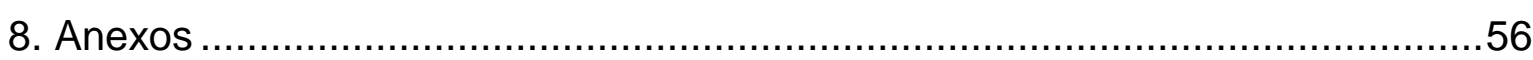




\section{Lista de figuras}

Figura 1: Organometálico isopropóxido de titânio.

Figura 2: Diagrama de blocos de um sistema típico, com um simulador com "hardware in the loop". 12

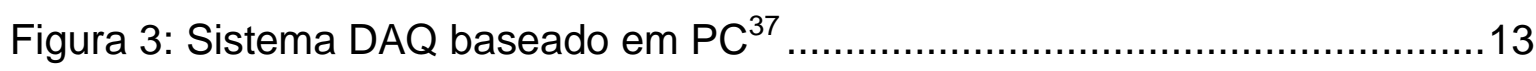

, neste trabalho aplicaram-se as seguintes condições: .17

Figura 4: Equipamento MOCVD existente no laboratório do CCTM, mostrado esquematicamente.

Figura 5: Equipamento MOCVD. (a) painel frontal; (b) parte traseira do painel frontal. 19

Figura 6: Forno. (a) forno aberto; (b) reator de quartzo posicionado dentro do forno. 19

Figura 7: Revestimento multicamada mostrado esquematicamente. .20

Figura 8: Pressão de vapor do isopropóxido de titânio em função da temperatura

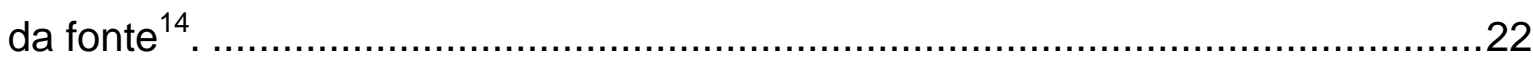

Figura 9: Diagrama de blocos da estrutura de montagem. ................................25

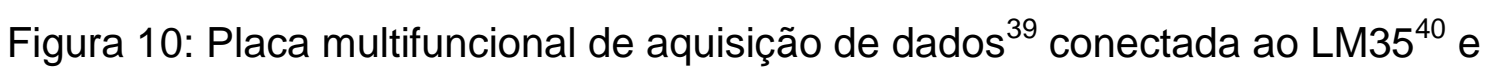
ao amplificador de reles, para a leitura de um termômetro e o acionamento de um rele.

Figura 11: Circuito amplificador utilizado para acionamento das válvulas solenoides .26

Figura 12: Sensor de temperatura, $\mathrm{LM} 35^{30}$.

Figura 13: Filme de $\mathrm{TiO}_{2}$ crescido por $1 \mathrm{~h}$ a $700^{\circ} \mathrm{C}$. (a) superfície; (b) secção transversal...... .28

Figura 14: Difratograma do filme de TiO2. .29

Figura 15: Filme de TiN crescido por $1 \mathrm{~h}$ a $700^{\circ} \mathrm{C}$. (a) superfície; (b) secção transversal. 29

Figura 16: Difratograma do filme de TiN obtido após $1 \mathrm{~h}$ a $700^{\circ} \mathrm{C}$. .30 
Figura 17: Filme composto por multicamadas (4 períodos) $\mathrm{TiO}_{2} / \mathrm{TiN}$ a $700^{\circ} \mathrm{C}$. (a) superfície; (b) secção transversal em imagem de elétrons secundários; (c) secção transversal em imagem de elétrons retro-espalhados.

Figura 18: Filme composto por multicamadas (8 períodos) $\mathrm{TiO}_{2} / \mathrm{TiN}$ a $700^{\circ} \mathrm{C}$. (a) superfície; (b) secção transversal em imagem de elétrons secundários; (c) secção transversal em imagem de elétrons retro-espalhados. .32

Figura 19: Montagem experimental do circuito. .33

Figura 20: Vista frontal, led's indicadores visuais de acionamento. .33

Figura 21: Arquivo com os parâmetros de teste .34

Figura 22: Tela principal, interface do usuário. 35

Figura 23: Status de teste. 36

Figura 24: Status do sistema. .36

Figura 25: Indicação da temperatura da linha dos gases.

Figura 26: Gráfico de acompanhamento da variação das temperaturas. Opção selecionada pelo botão "Gráfico" .37

Figura 27: Botões de Inicio, pausa, parada do teste. 38

Figura 28: Botões de acionamento manual das válvulas. .38

Figura 29: Seleção do teste 39

Figura 30: Ajuste de temperatura individual. 39

Figura 31: Botão de ajuste de temperatura. 39

Figura 32: Arquivo "Templimites.txt" com setup das temperaturas. 40

Figura 33: Fluxograma geral do programa 41

Figura 34: Rotina principal (main_ipen.c). .43

Figura 35: Inicialização: Lê tabela de parâmetros, inicializa placas, desliga reles e habilita leitura de temperatura. 44

Figura 36: Função IPEN_Teste: Após pressionar o botão "Inicio", ocorre o controle do ciclo térmico. .45

Figura 37: Função: Leitura da tabela de parâmetros e alocação na memória. .....46

Figura 38: Subrotina $R L \_n$ : Botão/função que liga/desliga reles 47

Figura 39: Subrotina EscDigital6008: Acesso a saídas. .48

Figura 40: Subrotina ThreadFunção: Faz a leitura/controle das temperaturas e fluxo de massa. 
Lista de tabelas

Tabela I: Condições de Teste . 22 


\section{Introdução}

A maioria dos materiais metálicos usados na tecnologia moderna requer determinadas propriedades da liga como um todo, e um diferente conjunto de propriedades de superfície. Os requisitos para a liga são tenacidade, resistência à tração, entre outros, enquanto que os de propriedades de superfície são resistência à oxidação, ao desgaste, à erosão, etc. ${ }^{1,2}$. É raro que essa combinação possa ser apresentada por um único material, daí a necessidade do uso de revestimentos, que têm ainda como vantagem não alterar as propriedades mecânicas e microestruturais das ligas.

As técnicas clássicas de revestimento como pintura, spray e imersão promovem camadas relativamente espessas $(0,1-1 \mathrm{~mm})$, que freqüentemente apresentam baixa aderência ao substrato. No caso de proteção contra corrosão, uma variedade de técnicas está disponível para aplicação de filmes finos aderentes (10 nm a alguns micrômetros), como implantação iônica ${ }^{3,4}$ sputtering $^{5}$, deposição química de vapores $(C V D)^{6}$, sol gel ${ }^{7}$ deposição química de organometálicos em fase vapor (MOCVD) $)^{7,8}$ entre outras. A técnica MOCVD tem sido usada recentemente para esse propósito, e tem promovido a obtenção de filmes de melhor qualidade que os obtidos por CVD convencional ou por métodos físicos. Além disso, a técnica MOCVD apresenta-se como uma alternativa competitiva porque é relativamente barata e mais fácil de ser implantada, em relação aos métodos de deposição física.

Revestimentos nanocristalinos são reconhecidos por exibirem dureza e resistência elevadas. Nas últimas décadas, aplicações específicas foram encontradas para revestimentos cerâmicos de alta dureza e alta resistência ao desgaste no setor industrial. Dentre estes se destacam os revestimentos de nitretos de metais de transição, que despertaram interesse especial devido a sua alta dureza, estabilidade térmica, aparência atrativa e por serem quimicamente inertes $^{9}$. Estruturas multicamadas, com períodos de super-rede da ordem de nanômetros, apresentam valores de resistência superiores a $40 \mathrm{GPa}^{9}$. O uso de revestimentos como TiN, TiCN e TiAIN aplicados sobre componentes estruturais é amplamente reconhecido por aumentar o desempenho de ferramentas de corte e mandris ${ }^{10}$. Makino et. al $(1998)^{11}$ mostram que uma pequena quantidade de 
oxigênio aumentava a dureza do TiN, tornando, o TiNO um candidato ideal para recobrir aços ou ferramentas de corte. Além disso, filmes finos de $\mathrm{TiO}_{2}$ e $\mathrm{TiN}$ são importantes para aplicações nas áreas de microeletrônica, óptica e médica ${ }^{12},{ }^{13}$. O interesse por filmes de TiNO aumentou nos últimos anos, porque a presença e o controle de oxigênio no nitreto de titânio conduz à formação de revestimentos com gradiente de função variando entre o isolante $\mathrm{TiO}_{2}$ e $\mathrm{o}$ condutor $\mathrm{TiN}$, e onde a resistividade varia em função da razão $\mathrm{N} / \mathrm{O}^{14}$.

Os sistemas computacionais desempenham um importante papel no controle de sistemas mecânicos típicos. A simulação de um sistema antes dos testes principais nem sempre ajuda, devido à ausência de condições reais relacionadas ao meio e ao tempo mapeado em termos de sinais analógicos e/ou digitais. Os testes tradicionais, muitas vezes referenciados como testes estáticos, consistem da avaliação de funcionalidades de um processo onde a ele são fornecidas entradas conhecidas e saídas mensuráveis. Devido ao lançamento de produtos mais sofisticados no mercado e à redução dos ciclos de desenvolvimento associados ao projeto, ocorre um aumento da necessidade de testes dinâmicos, onde o comportamento do processo é avaliado à medida em que os parâmetros de processo são alterados, de forma real ou simulada. Estas simulações minimizam riscos relacionados à segurança e custos, além de abranger maiores condições de testes quando comparados aos testes estáticos. A aplicação desta estratégia para testes dinâmicos é conhecida como simulação com "hardware in the loop (HIL)"15.

Nos capítulos a seguir estão apresentados revisão bibliográfica, objetivos, materiais e métodos, resultados e conclusões relativos à obtenção de filmes compostos por multicamadas $\mathrm{TiO}_{2} / \mathrm{TiN}$, bem como o desenvolvimento do processo de automação do equipamento MOCVD existente no Laboratório de Filmes Finos do Centro de Ciência e Tecnologia do Ipen. 


\section{Objetivos}

Esta dissertação teve por objetivos:

- Obtenção e caracterização de filmes com estrutura de multicamadas de $\mathrm{TiO}_{2} / \mathrm{TiN}$ depositados sobre Si monocristalino por meio da técnica MOCVD.

- Projeto da automação do equipamento MOCVD existente no Laboratório de Filmes Finos do Centro de Ciência e Tecnologia de Materiais do Ipen. 


\section{REVISÃO DA LITERATURA}

\subsection{Técnicas CVD e MOCVD}

\subsubsection{Estado da Arte}

A técnica CVD (deposição química em fase vapor) não é nova. Seu primeiro uso prático foi na década de 1880 para aumentar a resistência dos filamentos de lâmpadas incandescentes, por meio de revestimentos com carbono ou metal. Na mesma década, o processo foi utilizado para obtenção de níquel puro. A técnica CVD se desenvolveu muito lentamente nos 50 anos seguintes, quando seu uso limitou-se praticamente à metalurgia extrativa, na produção de metais refratários como tântalo, titânio e zircônio de alta pureza. Somente no final da $2^{\mathrm{a}}$. Guerra Mundial o avanço passou a ser mais rápido, com pesquisadores descobrindo suas vantagens no revestimento de peças de formas complexas ${ }^{16}$.

Nos anos 1960 foi introduzida a distinção entre os termos CVD e PVD (deposição física de vapores) para diferenciar os processos químicos dos processos físicos. A técnica CVD passou então a ser utilizada na fabricação de semicondutores e os revestimentos de TiC aplicados sobre ferramentas. $\mathrm{Na}$ década de 1980, o processo CVD passou a ser utilizado na deposição de carbono diamante. Nos anos 1990 houve a expansão do processo com o desenvolvimento de MOCVD (deposição química de vapores organometálicos) para deposição de metais e cerâmicas, e aprimorou-se o uso de CVD em componentes ópticos e eletrônicos ${ }^{16}$.

Atualmente, esta tecnologia vem se desenvolvendo rapidamente. Entretanto, foi necessário mais de um século de esforços científicos contínuos para que fosse atingido esse estado da arte. Apesar de todos os progressos obtidos, muitos desenvolvimentos precisam ser feitos, como a obtenção de maior controle da composição química no processo e a determinação da estrutura e das propriedades dos materiais depositados. Apesar de grandes avanços no entendimento dos mecanismos envolvidos, o processo necessita ainda de muitos desenvolvimentos experimentais. 


\subsubsection{Deposição química em fase vapor - O processo CVD}

CVD ou deposição química em fase vapor consiste em fazer com que o vapor de um composto volátil entre em contato com a superfície a ser recoberta. A temperatura do substrato fornece a energia de ativação necessária para induzir a reação química, que resulta num produto sólido e, em geral, facilita a difusão através da superfície os átomos depositados (quando a temperatura for suficientemente alta, da ordem de 1073-1273K) aumentando a aderência da camada depositada sobre o substrato ${ }^{8}$.

\subsubsection{Deposição química de organometálicos em fase vapor (MOCVD)}

MOCVD é uma área específica de CVD, que é relativamente nova. Sua primeira utilização foi relatada na década de 1960 para a deposição de fosfeto de índio e antimonieto de índio ${ }^{16}$. Estes primeiros experimentos demonstraram que a deposição de materiais semicondutores críticos poderia ser obtida a temperaturas inferiores às utilizadas no processo CVD $\left(>900^{\circ} \mathrm{C}\right)$ convencional, e o crescimento epitaxial poderia ser alcançado com sucesso. A qualidade e a complexidade dos equipamentos, bem como a diversidade e a pureza dos produtos químicos precursores têm melhorado constantemente. Desde então, a técnica MOCVD é usada em grande escala, particularmente em sistemas opto - eletrônicos e semicondutores ${ }^{16}$.

A deposição química em fase vapor que utiliza como fonte um composto organometálico é um processo atrativo para deposição de filmes finos dielétricos e outros revestimentos, porque necessita de temperaturas de crescimento relativamente baixas, apresenta altas velocidades de crescimento, e permite 0 recobrimento de substratos de formas complexas. No processo químico para deposição de filmes finos, a composição e a estrutura são determinadas pelos precursores químicos utilizados e pelas condições de deposição, como temperatura e pressão. 
As propriedades de um filme obtido por CVD (elétricas, ópticas, magnéticas e mecânicas) são determinadas por uma variedade de processos físico-químicos envolvidos no crescimento do filme ${ }^{17}$. A maioria das reações MOCVD ocorre em temperaturas entre 300 e $800^{\circ} \mathrm{C}$ e sob pressão variando entre menos de 1 torr até a atmosférica ${ }^{16}$.

\subsection{Organometálicos}

Os precursores são compostos organometálicos onde o átomo de um metal está ligado a um ou mais átomos de carbono de um grupo de hidrocarbonetos. São as matérias-primas para cada elemento ( $\mathrm{Al}, \mathrm{Ga}, \mathrm{In}, \mathrm{N}, \mathrm{Si}$, Mg e assim por diante). Eles podem se apresentar na forma sólida, líquida ou gasosa. Estes compostos devem ter boa volatilidade (a pressões acima de 0,1 torr e em torno de $300 \mathrm{~K}$ ), ter boa estabilidade térmica durante a sua evaporação e transporte na fase gasosa, e devem se decompor sem contaminar o filme em crescimento. Além disso, devem possuir alta pureza, não ser tóxico e não pirofóricos, quando possível. Para fornecer uma pressão de vapor estável, precursores líquidos são melhores do que sólidos e gasosos ${ }^{18}$.

Na figura 1 está apresentado, como exemplo, o composto organometálico isopropóxido de titânio $\mathrm{Ti}\left(\mathrm{OCH}\left(\mathrm{CH}_{3}\right)_{2}\right)_{4}$.
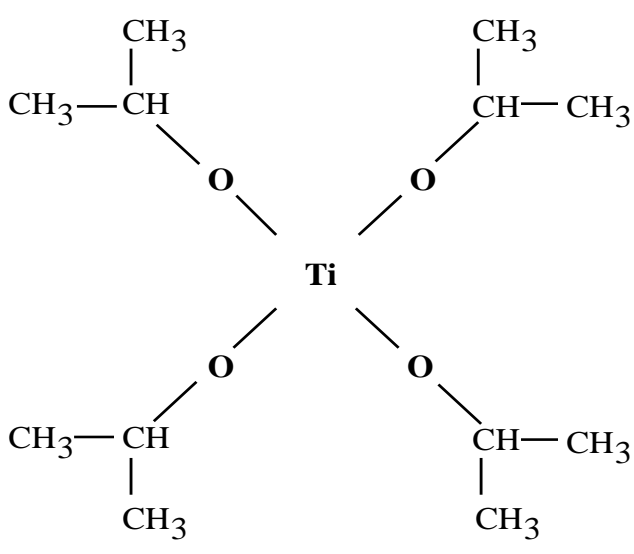

Figura 1: Organometálico isopropóxido de titânio. 


\subsection{Dióxido de titânio $\mathrm{TiO}_{2}$}

Filmes de dióxido de titânio são quimicamente estáveis, possuem alta constante dielétrica, alto índice de refração, excelente transmitância visual e, próximo às freqüências de infravermelho, possuem grande variedade de aplicações, incluindo revestimentos anti-reflexivo, sensores e fotocatalisadores. Um grande número de técnicas tem sido desenvolvidas para depositar filmes finos de $\mathrm{TiO}_{2}$. Dentre estas, deposição química em fase vapor (CVD) é uma das mais utilizadas, permitindo um controle rigoroso dos parâmetros de crescimento e, portanto, da estequiometria e da microestrutura.

$\mathrm{O} \mathrm{TiO}_{2}$ é conhecido por ter três fases alotrópicas: broquita, rutilo e anatase. A fase rutilo, formada em altas temperaturas, possui um índice de refração em torno de 2,7 enquanto a anatase possui um índice refração em torno de 2,5. A estrutura do filme depende da temperatura de deposição e das propriedades da superfície do substrato ${ }^{19}$.

Wicaksana e Kobayashi ${ }^{20}$ investigaram a deposição de $\mathrm{TiO}_{2}$ em substratos de vidro e Si por "sputtering" reativo, entre a temperatura ambiente e $400^{\circ} \mathrm{C}$. Eles constataram que a fase anatase formada em temperaturas abaixo de $400^{\circ} \mathrm{C}$ consistia de uma mistura anatase-rutilo e os filmes depositados a $400^{\circ} \mathrm{C}$ consistiam de rutilo ${ }^{19}$.

\subsection{Nitreto de titânio TiN}

Revestimentos de nitreto de titânio possuem excelente resistência à corrosão e à erosão, alta temperatura de sublimação, dureza elevada e boas propriedades ópticas e eletrônicas. São utilizados em dispositivos microeletrônicos, e para melhorar o desempenho e prolongar a vida útil de ferramentas de corte. Filmes finos de TiN são comumente utilizados como revestimento protetor resistente à corrosão.

Muitas técnicas, como "magnetron sputtering", deposições por feixe de ions, plasma e CVD têm sido usadas para crescer filmes finos de $\mathrm{TiN}^{21}$. 


\subsection{Multicamadas}

O desenvolvimento de superfícies resistentes ao desgaste tem sido um item crítico, e ainda permanece como um ponto chave para a indústria de manufatura $^{22}$. Nas últimas décadas, revestimentos cerâmicos de nitretos como TiN e CrN, depositados por deposição física de vapores (PVD) ou deposição química de vapores (CVD) encontraram muitas aplicações como revestimento de ferramentas de corte e equipamentos de usinagem ${ }^{23,24}$. Entretanto, devido ao desenvolvimento de novos processos, como os que envolvem altas velocidades ou usinagem a seco, há ainda interesse industrial em revestimentos protetores que melhorem as propriedades de resistência ao desgaste, dureza e tenacidade à fratura ${ }^{25,26}$. Nesse contexto, revestimentos compostos por multicamadas nanométricas têm recebido atenção, porque têm flexibilidade para combinar dois materiais com estruturas diferentes e propriedades, que podem trazer aos novos sistemas, não apenas as vantagens de cada constituinte, mas também algumas características superiores a qualquer outro componente ${ }^{27}$. As estruturas multicamadas nanométricas são geralmente obtidas pela deposição sequencial de dois materiais diferentes, de dimensões nanométricas, sobre a superfície de um substrato. A espessura de cada par de camadas desempenha um papel importante nas propriedades dos revestimentos multicamadas ${ }^{28}$. Vários sistemas multicamadas, incluindo TiN/CrN, TiAIN/CrN, CrN/AIN e TiN/ZrN, já foram desenvolvidos e apresentaram melhores propriedades quando comparados a constituintes binários ${ }^{25,29,30,31}$.

\subsection{Sistemas computacionais}

Os sistemas computacionais estão presentes no nosso cotidiano já faz algum tempo. A indústria, de um modo geral, é o maior usuário, seja para gerar tecnologia, testar seus produtos, gerenciar a logística, etc.

Antigamente, testar um produto requeria muita mão-de-obra e poucos equipamentos, e não havia confiabilidade nos resultados. A evolução tecnológica força novos conceitos de projetos, o que impulsiona o desenvolvimento de novas ferramentas para auxiliar os cientistas e engenheiros. 
$\mathrm{Na}$ obtenção de revestimentos compostos por multicamadas, obtidos pelo processo MOCVD, não é diferente. Durante o experimento, o processo manual exige habilidade do operador para controlar a seleção dos gases a intervalos regulares de tempo, para que se formem as camadas alternadas que compõem o filme. Tal procedimento influencia, e pode gerar um equívoco do operador no gerenciamento do intervalo de abertura e fechamento das válvulas.

A ferramenta Labwindos/CVI® da National Instruments surge como opção para gerenciar todo o sistema, minimizando a influência do operador, e tornando possível a utilização de intervalos de tempo de abertura e fechamento de válvulas menores que um minuto.

\subsubsection{Simulação}

Simulação é muitas vezes utilizada para entender o comportamento de um sistema ou para predizer uma saída sob diferentes influências internas e/ou externas. Porém, se a simulação está sendo usada para provar a viabilidade de controle, o risco de investimento pode ser reduzido utilizando-se uma abordagem baseada em simulação com "hardware in the loop". Para a maioria dos sistemas reais, existem características que são desconhecidas ou muito complexas para serem modeladas somente através de simulação. Se, por exemplo, deseja-se estabelecer controle sobre o sistema de posicionamento, seria bastante arriscado ter que construir todo o hardware no início sem considerar o sistema como um todo. Neste caso, uma boa prática de engenharia seria iniciar com uma simulação pura e, à medida que os componentes forem estabelecidos, eles podem ser fabricados e recolocados no laço de controle. Uma vez que os componentes físicos são adicionados ao laço de controle, características não modeladas podem ser investigadas e o controle pode ser refinado.

O uso de simulação com "hardware in the loop" diminui gastos e a quantidade de interações para a fabricação de maquinário e suas partes, além de tornar o desenvolvimento mais eficiente. Máquinas baseadas em processadores Pentium ${ }^{\circledR}$, por exemplo, com clock na ordem de Ghz, apresentam o poder de processamento necessário a um baixo custo, além das interfaces analógicas ou digitais de entrada/saída, cujos preços vêm diminuindo gradativamente. Desse 
modo, é possível adquirir um sistema completo envolvendo computador, software e dispositivos de entrada/saída por custos muito atrativos.

"Hardware in the loop" é utilizado em softwares gráficos que auxiliam os engenheiros de controle a desenvolver sistemas rapidamente, utilizando apenas o modelo conceitual. Neste ambiente de desenvolvimento o engenheiro de controle não é necessariamente o responsável por implementar a programação. Sua função será de modelar as interações e fluxos através de diagramas de blocos. 0 engenheiro de controle poderá dedicar-se a outras características do projeto, evitando levar horas de escrita e/ou depuração de códigos ou mesmo ter que lidar com as complexidades dos sistemas de tempo real. Desse modo, o término de um projeto de sistema de controle pode ser completado em um prazo menor.

Eventualmente, o projeto precisará ser transferido para o sistema final (target). Quando o algoritmo de controle é conhecido, passa a ser conhecida também sua carga computacional. Portanto, selecionar um processador adequado para a execução das tarefas torna-se mais fácil. Técnicas de validação de componentes, seja de forma unitária ou em nível de sistema, são facilmente aplicadas ao código, utilizando o controlador do simulador como uma referência. Neste estágio, o risco de desenvolvimento pode ser apenas afetado pelos prazos, não pela tecnologia.

A técnica de simulação com "hardware in the loop" aplica-se a todos os sistemas, sejam eles grandes ou pequenos, processos industriais e mesmo durante o desenvolvimento de novos produtos. Onde quer que exista interação entre simulação e o mundo real, existe uma oportunidade para a abordagem de simulação com "hardware in the loop"15.

\subsection{2. "Hardware in the loop (HIL)"}

HIL refere-se a uma simulação onde alguns dos componentes são reais e não simulados. É considerada a técnica mais segura e de mais baixo custo para teste de controle de processos reais em ambientes virtuais. A maioria dos componentes reais é substituída por modelos matemáticos e os componentes a testar são inseridos na malha fechada. Uma das razões para inserir componentes 
numa simulação surge, muitas vezes, pela inexistência de um conhecimento cabal das suas características, ou estas são muito complexas, ou então quando existe a necessidade de teste dos próprios componentes reais, como é o caso do teste de controladores. Pode-se, por exemplo, partir de uma simulação pura em tempo real, com os modelos de todos os componentes do sistema, de modo a cumprir determinadas especificações. À medida que vão se ajustando os parâmetros de processo, é possível, por exemplo, reduzir o número de ensaios na obtenção do resultado esperado ${ }^{15}$.

A indústria aeroespacial está entre as primeiras que desenvolveram este tipo de simulação, com o objetivo de desenvolver formas viáveis de realizar testes em sistemas de controle de vôo, muito embora, desde então, as aplicações passaram a ser bastante diversificadas, como indicado por Maclay ${ }^{32,33,34}$.

A tecnologia de simulação HIL pode ser encontrada onde são necessários testes mais realísticos com componentes de um sistema antes de sua construção final, como, por exemplo, na modelagem do processo de fabricação de motores diesel, da fundição ao armazenamento do bloco após a usinagem.

A arquitetura de simulação HIL deve manter um estado simulado do mundo, que deve ser calibrado com o mundo real, favorecendo a análise de dados. Quando aplicada a revestimentos nanoestruturados, consiste de um projeto colaborativo entre diferentes ciências e áreas de conhecimento, incluindo conceitos encontrados na engenharia mecatrônica, software e materiais ${ }^{15}$.

A HIL é, também, uma ferramenta bastante útil para avaliação e desenvolvimento de controladores, proporcionando um risco nulo na experimentação de diferentes técnicas e metodologias de controle sem necessidade da plataforma real para teste ${ }^{35}$. Desta forma, é possível poupar investimentos e evitar potenciais acidentes resultantes de erros no projeto inicial dos controladores, permitindo, assim, a identificação e eliminação desses erros.

A figura 2 mostra algumas possibilidades de interação de componentes reais com versões simuladas de outros componentes num sistema de controle típico. Como se pode observar, alguns caminhos na malha não são possíveis. Por exemplo, não é possível um processo real ser monitorado através de sensores simulados ou atuadores simulados atuarem em processos reais. A técnica denominada de "load simulation" consiste na utilização de um processo simulado para avaliação de desempenho de atuadores reais ${ }^{36}$. 
O monitoramento de processos simulados através de sensores reais pode ser utilizado quando se quer avaliar o desempenho de um determinado sensor. Neste caso, é necessária uma interface adequada, que pode envolver um atuador real para converter os resultados da simulação em quantidades mensuráveis pelo sensor.

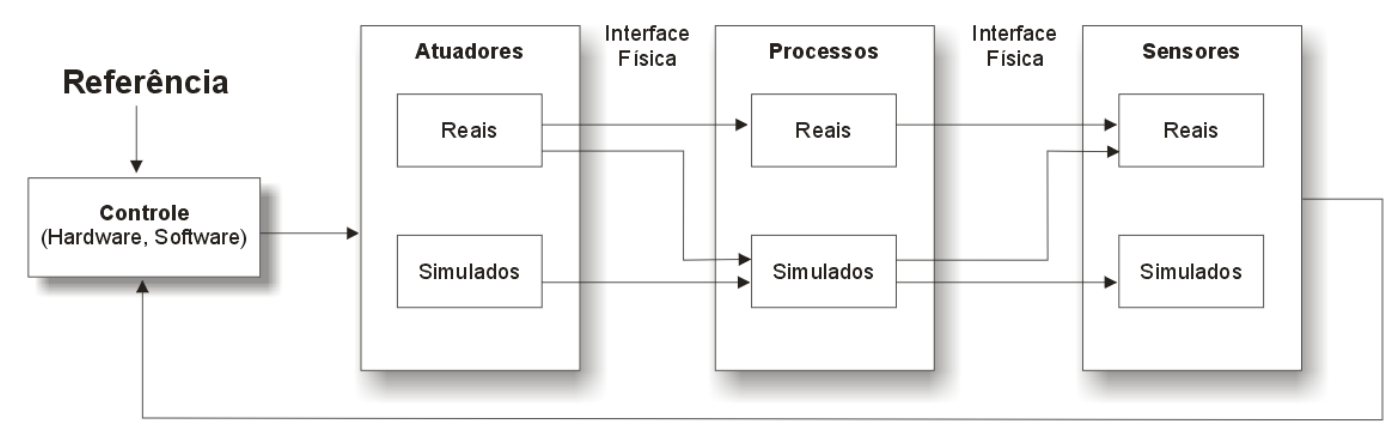

Figura 2: Diagrama de blocos de um sistema típico, com um simulador com "hardware in the loop".

\subsubsection{Simulação com "Hardware in the Loop"}

No processo de simulação com "hardware in the loop" (HIL), o controlador é executado pelo computador de forma a garantir o escalonamento de entrada e saída (I/O - Input ou Output). Requisitos de hardware como o poder de processamento e interfaceamento com circuitos que disponibilizam sinais analógicos ou digitais devem ser levados em consideração.

\subsection{Aquisição de dados}

Atualmente, a maioria dos cientistas e engenheiros usam computadores pessoais (PCs) com PCl, PXI/CompactPCI, PCMCIA, USB, IEEE 1394, ISA ou portas paralelas ou seriais para aquisição de dados no laboratório de pesquisa, teste e medição, e automação industrial. Muitos aplicativos usam dispositivo "Plug-in" para obter dados e transferi-los diretamente ao computador, outros usam 
hardware de aquisição de dados (DAQ) no PC, que está ligado através da porta serial ou paralela ${ }^{37}$.

Aquisição de dados é a captura de sinais provenientes de fontes de medição do mundo real e a digitalização desses sinais para armazenamento, análise e apresentação em um computador pessoal (PC). Luz, temperatura, pressão e torque são alguns dos muitos diferentes tipos de sinais que podem ser conectados a um sistema de aquisição de dados. Além de aquisição de dados, tal sistema também é usado para gerar os sinais elétricos.

O projeto e a produção de automóveis, por exemplo, dependem da aquisição de dados. Os engenheiros utilizam a aquisição de dados para testar os componentes do automóvel. O sistema pode ser usado para teste de fadiga mecânica, ruído de vento, durabilidade, vibração e temperatura do motor. Os analistas e engenheiros, em seguida, podem usar esses dados para otimizar o design do primeiro protótipo do veículo. O protótipo, em seguida, pode ser monitorado em muitas condições diferentes em uma faixa de teste, enquanto que informações são coletadas por meio de aquisição de dados. Depois das interações necessárias e mudança de design, o carro está pronto para produção. Os dispositivos de aquisição de dados podem monitorar as máquinas que montam o carro, e eles podem garantir que o carro montado atenda às especificações necessárias ${ }^{38}$.

A obtenção de resultados adequados de um sistema de aquisição de dados depende de cada um dos seguintes elementos sistema: PC, transdutores, condicionadores de sinais, placas de aquisição e software ${ }^{37}$, conforme mostra a figura 3.

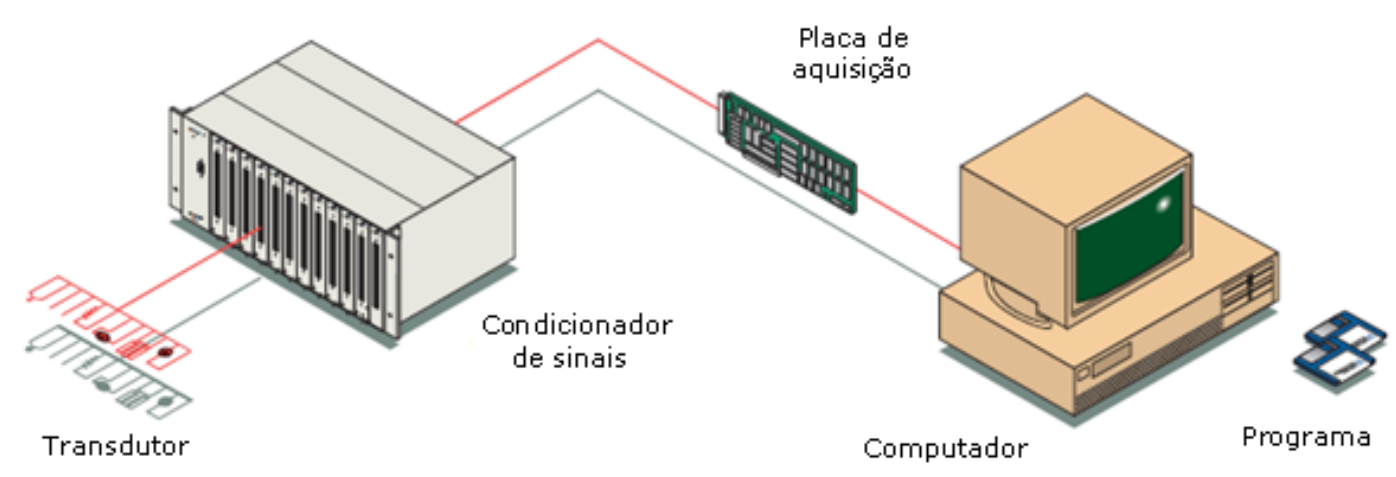

Figura 3: Sistema DAQ baseado em $\mathrm{PC}^{37}$ 


\subsection{Transdutores e Condicionadores de Sinal}

Transdutores captam fenômenos físicos e produzem sinais elétricos que 0 sistema DAQ (data acquisition) mede. Por exemplo, termopares, sensores de temperatura por resistência (RTDs), termistores e sensores $\mathrm{Cl}$ (circuito integrado) convertem temperatura em um sinal analógico que podem ser medidos em um conversor analógico-digital $(A / D)$.

Condicionadores de sinais consistem de filtros, amplificadores atenuadores ou diferentes formas de sinais, localizados entre a planta e o computador que comporta o software de execução. São compostos, basicamente, de componentes discretos (resistores, capacitores, amplificadores operacionais, etc).

Os sinais elétricos gerados pelos transdutores devem ser otimizados para o limite, "range", de entrada do dispositivo DAQ. A placa de aquisição é responsável por condicionar, amplificar sinais de baixo nível e, em seguida, isolálos e filtrá-los para medições mais precisas.

O condicionamento de sinais exige que algumas etapas sejam seguidas:

- Amplificação: É a mais comum. Sinais de termopares são muito baixos e necessitam ser amplificados para aumentar a resolução e diminuir o ruído.

- Isolação: É necessário isolar os sinais dos transdutores do computador para evitar um eventual curto-circuito.

- Filtragem: É a remoção de sinais indesejáveis, como por ex. ruído.

- Linearização: Muitos transdutores, como termopares, possuem uma resposta não-linear. Para corrigir essas medidas os aplicativos incluem rotinas $^{37}$.

\subsection{Máquina de Estados}

Máquina de estados é uma modelagem de um comportamento, composto por estados, eventos e ações, como descrito a seguir. 
"Estado" é um termo abstrato. Estados descrevem o status de uma parte da programação e estão sujeitos a alterações ao longo do tempo. Um estado armazena informações sobre o passado, isto é, ele reflete as mudanças desde a entrada num estado, no início do sistema, até o momento presente.

"Eventos" são ocorrências no tempo que influenciam o código controlado pela máquina de Estado. Um evento importante é o evento "Resposta recebida".

Esta ocorrência externa informará a máquina de Estado que ocorreu o evento correto e uma transição dos estados agora é apropriada. Os eventos podem ser gerados internamente pelo código controlado pela máquina de estado.

"Ações" são respostas dos eventos, que podem ou não afetar o código externo para a máquina de Estado. A máquina de estado determina quais ações devem ser tomadas quando um determinado evento ocorre. A decisão de que medidas devem ser tomadas é derivada de duas partes da informação: o estado atual e o evento que ocorreu.

A própria máquina de estados sempre faz alterações de estado. $O$ estado atual nem sempre vem do código externo para a máquina de estado. As únicas informações que o código externo deve fornecer ao estado de máquina é um evento que ocorreu ${ }^{15}$.

\subsection{Programa de controle}

Sistemas operacionais orientados a eventos como, por exemplo, Microsoft Windows $\AA^{8}$ 95/98/NT/2000/XP, Linux ${ }^{35}$ e BSD $^{36}$ são direcionados a responder apenas a entradas externas como aquelas iniciadas por um usuário (toque do teclado, clique do mouse, etc). De fato, estes sistemas operacionais são tipicamente gráficos em natureza e freqüentemente multitarefa, implicando que múltiplas aplicações ou tarefas gráficas possam demandar tempo do processador durante pontos críticos na operação da planta.

O desenvolver do software do sistema de controle freqüentemente corresponde à fase mais complexa e demorada do projeto, devido à seleção da estrutura do programa, escrita e depuração do código e às modificações do circuito durante o desenvolvimento. 


\section{Materiais e Métodos}

\subsection{Equipamento MOCVD}

$\mathrm{Na}$ figura 4 está mostrado esquematicamente o equipamento para obtenção de filmes por meio da técnica MOCVD, existente no Laboratório de Filmes Finos do CCTM. O equipamento tem como principais componentes uma câmara de reação, que consiste em um reator de quartzo aquecido por um forno infravermelho, e uma bomba de vácuo que mantém a câmara de reação sob pressão inferior à atmosférica. Permite o uso de três precursores organometálicos diferentes, além de amônia. Os precursores organometálicos, bem como as linhas de condução de gás, são mantidos aquecidos. O gás vetor utilizado é $\mathrm{N}_{2}$. Uma bomba de palhetas é utilizada para manter o sistema em vácuo dinâmico. A bomba utilizada possui uma vazão de $40 \mathrm{~m}^{3} / \mathrm{h}$. Uma válvula de agulha está instalada na entrada do reator e sua função é manter as linhas à pressão atmosférica, enquanto trabalha-se a uma pressão menor dentro do reator.

As fontes são mantidas a uma temperatura suficiente para que seja atingida a pressão de vapor adequada a cada precursor (aproximadamente $40^{\circ} \mathrm{C}$ para isopropóxido de titânio (TiP). Todas as linhas de gás são aquecidas por meio de cordões de aquecimento, colocados ao redor das tubulações de gás. Este sistema de aquecimento evitará que vapores organometálicos se condensem antes que atinjam o porta-amostra.

O controle da temperatura das linhas é feito por controladores digitais com saída do tipo PWM (modulação por largura de pulso), ajustados para $75^{\circ} \mathrm{C}$ e o aquecimento do banho termostático do TiP é controlado externamente.

O equipamento possui válvulas de esfera manual na entrada de gases, válvulas do tipo agulha para ajuste do fluxo dos gases, fluxômetros de massa e válvulas eletropneumáticas em cada linha. Na condição inicial todos os gases estão direcionados para a linha "BY PASS".

Os números entre colchetes são referentes aos números dos círculos na figura 4. 
A regulagem do fluxo dos gases e da pressão das linhas é feita sempre com a válvula direcionada à linha do "BY PASS" [4].

Para efetuar o recobrimento de $\mathrm{TiO}_{2}$ utiliza-se a linha [2], gás de arraste, e a linha [3]. A válvula [2] se fecha, as duas válvulas [1] e a válvula [3], by pass, se abrem simultaneamente. $O$ nitrogênio passa pelo borbulhador e sai carregando 0 precursor, que é então enviado para o reator [5].

Para efetuar o recobrimento de TiN utilizam-se as linhas [1], [2] juntamente com a linha [3] e abre-se a válvula [3], by pass. Amônia é enviada para o reator [5], juntamente com o nitrogênio que transporta o precursor.

As linhas sem numeração, trimetil ítrio e zircônio, não estão sendo utilizadas neste trabalho.

Para elaborar o revestimento multicamadas alterna-se a passagem da amônia para o reator através da válvula [3], by pass da linha [1]. Ou seja, durante a obtenção da camada de $\mathrm{TiO}_{2}$, a válvula de admissão de amônia permanece na posição fechada. Para a obtenção da camada de TiN, a válvula é aberta.

Em referência à figura 2, neste trabalho foram aplicadas as seguintes condições:

\section{Atuadores:}

- Reais: Reles de acionamento das válvulas

- Simulado: Botão de inicio do processo na tela do principal

\section{Processo:}

- Simulado: seqüência de deposição

\section{Sensores:}

- Reais: Sensor de temperatura, LM35, nas linhas dos gases

- Simulado: Números aleatórios para simular a variação de temperaturas

Nas figuras 5 e 6 estão mostrados os painéis do equipamento MOCVD e o forno. 


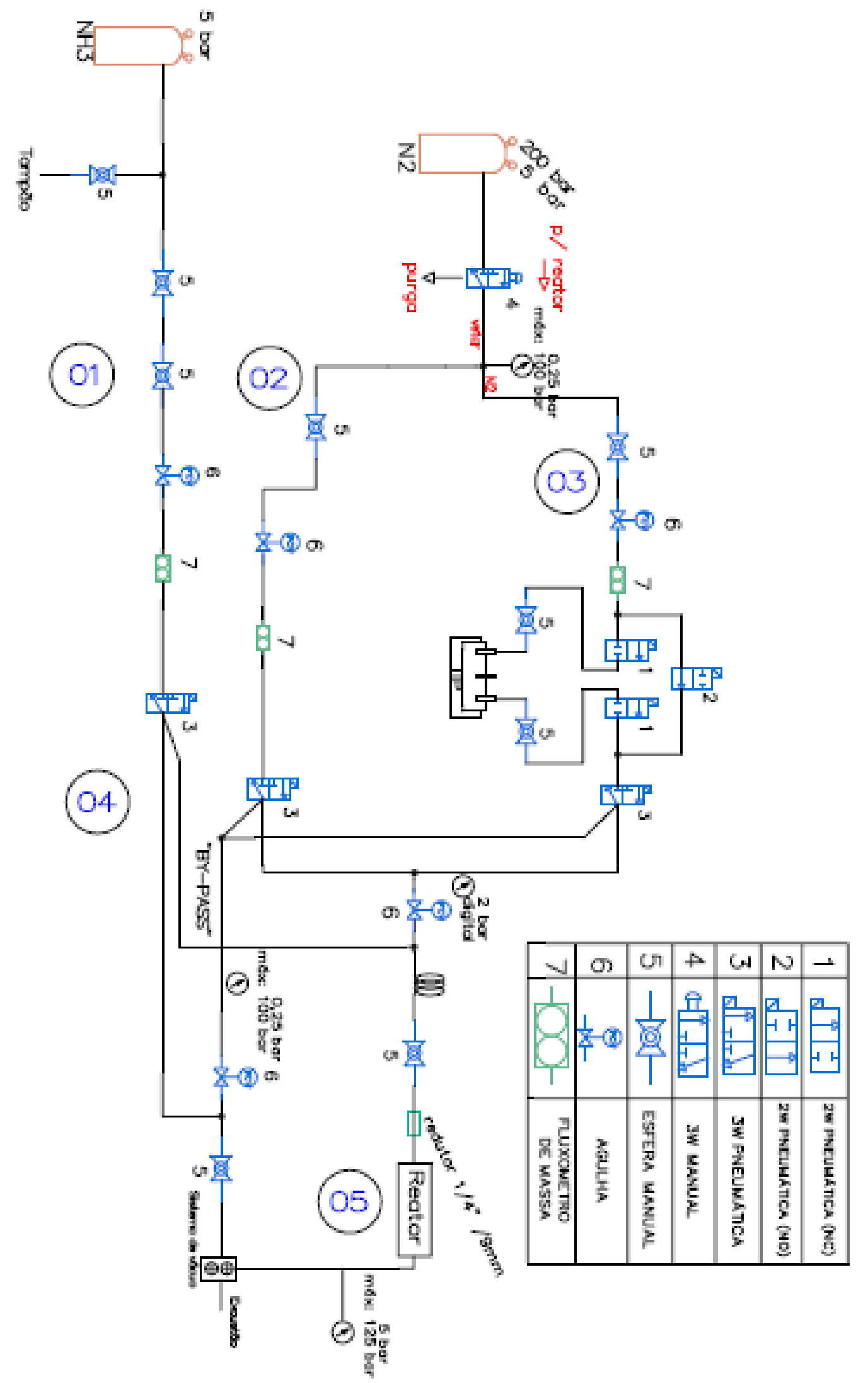

Figura 4: Equipamento MOCVD existente no laboratório do CCTM, mostrado esquematicamente. 

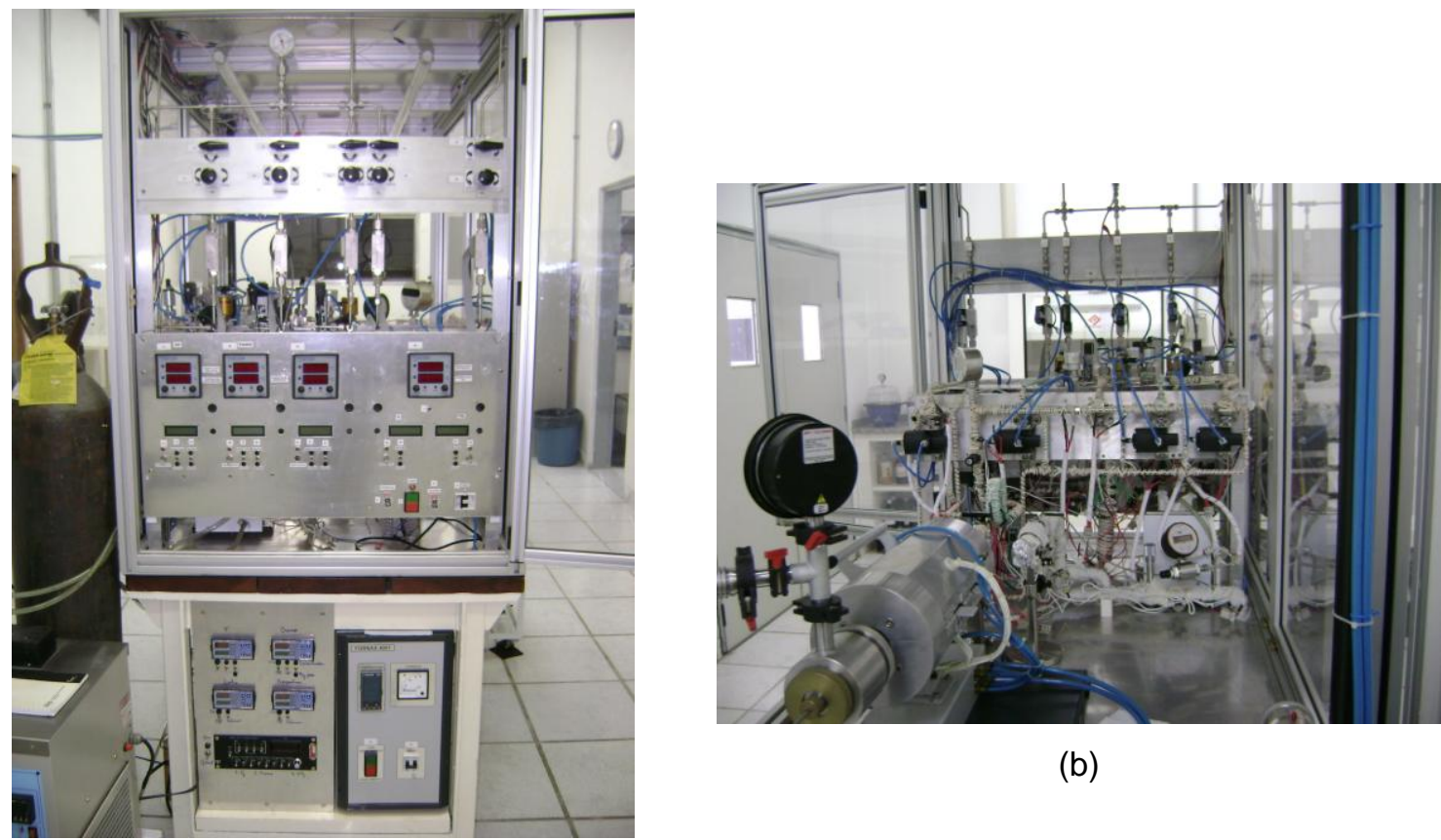

(b)

(a)

Figura 5: Equipamento MOCVD. (a) painel frontal; (b) parte traseira do painel frontal.
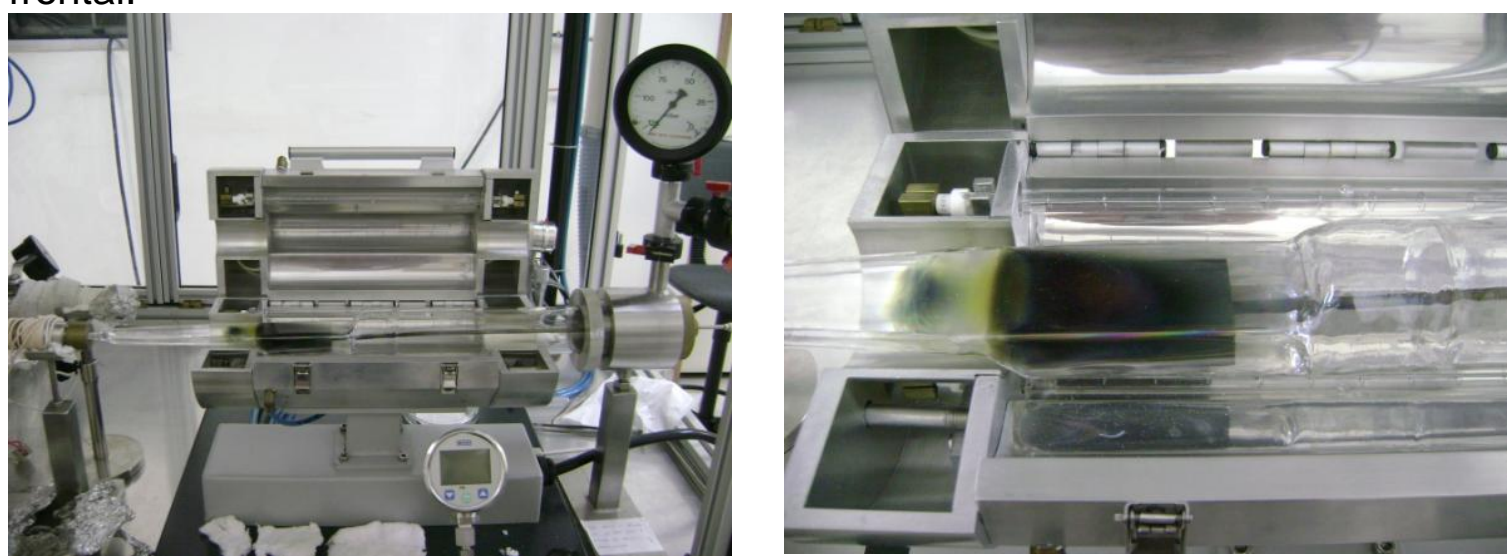

Figura 6: Forno. (a) forno aberto; (b) reator de quartzo posicionado dentro do forno.

\subsubsection{Parâmetros de Deposição}

Dentre os vários parâmetros que regem o crescimento por deposição química em fase vapor, os mais importantes neste sistema são:

Temperatura de crescimento: A eficiência da pirólise do precursor diminui quando a temperatura diminui. A utilização de substratos metálicos limita a temperatura de deposição 
Pressão total dentro do reator: a redução da pressão total aumenta a velocidade de acesso da fase gasosa à superfície do substrato, e por conseqüência evita a pirólise prematura dos reagentes. A pressão varia de acordo com as possibilidades oferecidas pela bomba existente no sistema.

Fluxo dos reagentes: diminuindo o fluxo total, as pressões parciais dos reagentes aumentam, e por conseqüência aumenta a velocidade de deposição.

Temperatura do banho termostático: a temperatura determina a pressão de vapor do precursor organometálico dentro da fonte, e por conseqüência, a quantidade de precursor capaz de ser conduzido pelo gás vetor até a câmara de reação. A temperatura necessária varia de acordo com o organometálico utilizado.

\subsection{Obtenção de filmes multicamadas $\mathrm{TiO}_{2} / \mathrm{TiN}$}

$\mathrm{O}$ crescimento de filmes compostos por multicamadas $\mathrm{TiO}_{2} / \mathrm{TiN}$ foi feito em uma única etapa. Tal procedimento foi possível através da admissão ou não de amônia no sistema, a intervalos regulares. Foram utilizados substratos monocristalinos de $\mathrm{Si}$ (100). A figura 7 mostra esquematicamente a estrutura do revestimento.

\begin{tabular}{|c|}
\hline $\mathrm{TiN}$ \\
\hline $\mathrm{TiO}_{2}$ \\
\hline $\mathrm{TiN}$ \\
\hline $\mathrm{TiO}_{2}$ \\
\hline $\mathrm{TiN}$ \\
\hline $\mathrm{TiO}_{2}$ \\
\hline $\mathrm{TiN}$ \\
\hline $\mathrm{TiO}_{2}$ \\
\hline Substrato \\
\hline
\end{tabular}

Figura 7: Revestimento multicamada mostrado esquematicamente.

Para a obtenção de $\mathrm{TiO}_{2}$ utiliza-se apenas o isopropóxido de titânio como fontes tanto de titânio quanto de oxigênio. Em seguida, adiciona-se ao sistema 
$\mathrm{NH}_{3}$ para a obtenção de TiN. Trata-se, portanto, de crescimentos utilizando isopropóxido de titânio e amônia, que são introduzidos no sistema simultaneamente, e são misturados antes de atingirem a câmara de reação. Para a obtenção dos sistemas multicamadas $\mathrm{TiO}_{2} / \mathrm{TiN}$ é necessário a abertura e o fechamento da válvula de admissão de amônia. Os tempos de permanência nas posições aberta ou fechada devem ser rigorosamente controlados e monitorados, para que as camadas tenham interfaces abruptas e para que a espessura de cada uma das camadas se repita.

\subsection{Substrato}

Foi utilizado substrato de Si (100), diâmetro de 2", Tipo N (dopado com fósforo), resistência de 1 a 4 ohms e espessura de $275+/-25 \mu \mathrm{m}$ em todos os testes.

Os substratos foram clivados em peças menores com auxílio de pinça e bisturi. A seguir, as peças foram lavadas por 3 minutos em uma solução de $5 \%$ $\mathrm{H}_{2} \mathrm{SO}_{4}$ em água deionizada. Foram enxaguados em água deionizada em abundância e secas com nitrogênio analítico. Estes substratos foram levados imediatamente ao reator.

\subsection{Precursores}

$\mathrm{O}$ organometálico isopropóxido de titânio $\mathrm{Ti}\left(\mathrm{OCH}\left(\mathrm{CH}_{3}\right)_{2}\right)_{4}$ foi utilizado como precursor tanto de $\mathrm{Ti}$ como de oxigênio. $\mathrm{O}$ nitrogênio analítico foi utilizado tanto como gás de arraste quanto como gás vetor. A amônia é utilizada como precursor de nitrogênio.

A temperatura do banho termostático de isopropóxido de titânio é controlada para determinar a pressão de vapor do organometálico. O gráfico da pressão de vapor de isopropóxido de titânio, em função a temperatura do banho, é mostrado na figura 8 , e segue a lei: 
$\log _{10} \mathrm{P}($ Torr $)=8,325-(2750 / \mathrm{T}(\mathrm{K}))$

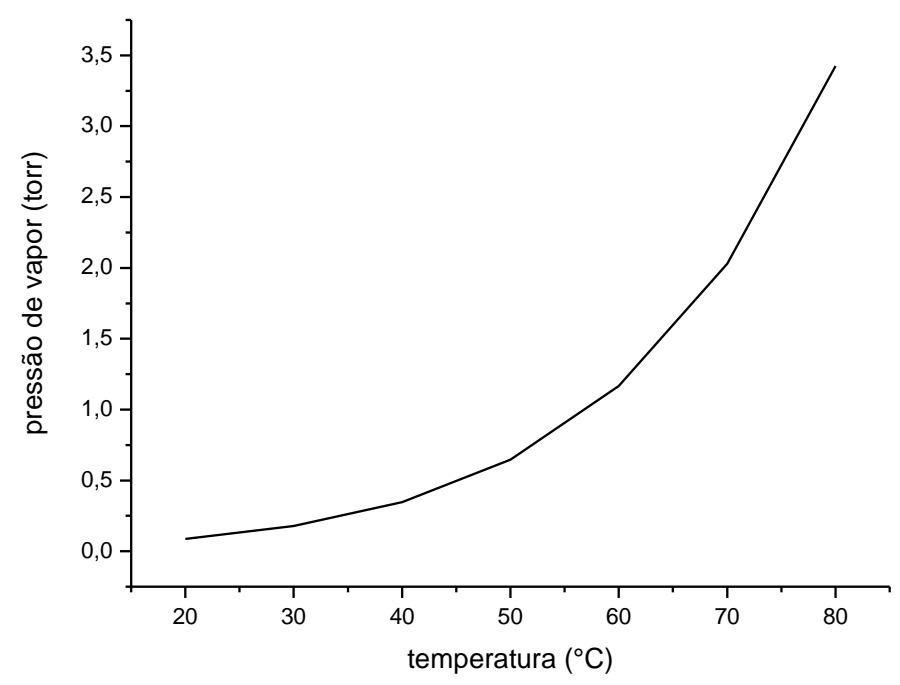

Figura 8: Pressão de vapor do isopropóxido de titânio em função da temperatura da fonte ${ }^{14}$.

\subsection{Parâmetros de processo}

Os testes para obtenção de camadas de $\mathrm{TiO}_{2}$ e $\mathrm{TiN}$ foram realizados, nas condições mostradas na Tabela I:

Tabela I: Condições de Teste

\begin{tabular}{|l|c|c|}
\hline & $\mathrm{TiO}_{2}$ & $\mathrm{TiN}$ \\
\cline { 2 - 3 } Tempo de deposição & 1 hora & 1 hora \\
\hline Temp. fonte $\left({ }^{\circ} \mathrm{C}\right)$ & 38 & 38 \\
\hline Temp. Substrato $\left({ }^{\circ} \mathrm{C}\right)$ & 700 & 700 \\
\hline Pressão do reator (mbar) & 100 & 100 \\
\hline Fluxo do $\mathrm{N}_{2}(\mathrm{l} / \mathrm{min})$ & 0,5 & 0,5 \\
\hline Fluxo do $\mathrm{TiP}(\mathrm{l} / \mathrm{min})$ & 0,5 & 0,5 \\
\hline Fluxo do $\mathrm{NH}_{3}(\mathrm{l} / \mathrm{min})$ & - & 0,5 \\
\hline
\end{tabular}


Para a obtenção de multicamadas, adotou-se a espessura de TiN igual a 3 vezes a espessura de $\mathrm{TiO}_{2}$. Dessa forma:

- Multicamadas com 4 períodos: A válvula de admissão de amônia permanece aberta por 9 minutos e fechada por 3 minutos. Esse procedimento é repetido por 4 vezes.

- Multicamadas com 8 períodos: A válvula de admissão de amônia permanece aberta por 4 minutos e fechada por 1,5 minutos. Esse procedimento é repetido por 8 vezes.

Enquanto a válvula de admissão de amônia está fechada o filme de $\mathrm{TiO}_{2}$ cresce sobre o substrato, quando a válvula está aberta cresce o filme de TiN

\subsection{Caracterização das amostras}

\subsubsection{Caracterização por Microscopia eletrônica de varredura com emissão de campo (MEV-FEG)}

As amostras destinadas à observação da superfície, para a caracterização da morfologia, foram recobertas com platina e levadas diretamente ao MEV-FEG. Foi utilizado um equipamento FEI - Quanta 600F.

Para determinação da velocidade de crescimento dos filmes foram analisadas as secções transversais das amostras que, após clivagem, foram recobertas com platina e levadas ao MEV-FEG. Neste caso, foram utilizadas imagens de elétrons secundários e elétrons retro-espalhados.

A velocidade de crescimento dos filmes foi estimada com base na medida da espessura, dividido pelo tempo de crescimento. 


\subsubsection{Difração de raios-X}

Para a identificação das fases formadas foi utilizado um difratômetro de raios-X de marca Rigaku. Foi utilizado um tubo de CuK $\alpha$ com passo de 0,05으 e tempo de aquisição de 10s.

\subsection{Controle de abertura e fechamento das válvulas}

O equipamento MOCVD foi concebido de forma a comportar sua automação. É dotado de controladores eletrônicos de temperatura e eletroválvulas para controle da admissão dos precursores. Com base nas dificuldades experimentais em se controlar a abertura e fechamento das válvulas, a automação deste processo surgiu como uma adaptação necessária.

Para viabilizar a obtenção de revestimentos multicamadas com períodos de alguns nanômetros, faz-se necessário o desenvolvimento de hardware e programa, que permita abrir e fechar as válvulas a intervalos regulares, já que manualmente tal procedimento é impreciso. Para tanto, foi feito um estudo do equipamento MOCVD existente no IPEN, definição das adaptações necessárias no circuito eletrônico e elaboração do programa de controle.

$\mathrm{Na}$ automação do processo, foi utilizado o conceito de máquina de estados para gerenciar o sistema. Máquina de estados é uma ferramenta de desenvolvimento usada em várias plataformas de software porque é de fácil manutenção, fácil documentação e o código pode ser reutilizável.

Foi utilizada simulação com "hardware in the loop" para desenvolver e testar o sistema. 


\subsubsection{Estrutura de montagem}

A figura 9 mostra a estrutura de montagem da automação do equipamento MOCVD.

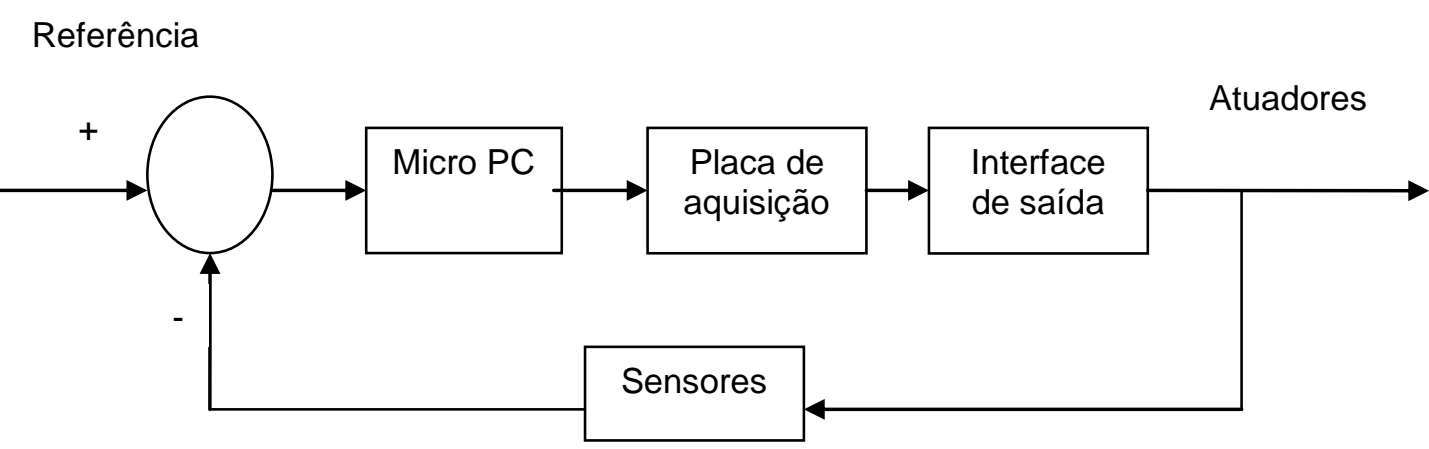

Figura 9: Diagrama de blocos da estrutura de montagem.

Onde:

1.Micro PC: Computador controlador do processo

2.Placa de aquisição: Placa de aquisição contendo E/S (entrada/saída) e A/D (analógico/digital)

3.Interface de saída: Bastidor com o circuito de chaveamento das válvulas

4.Atuadores: Válvulas pneumáticas

5.Sensores: Sensores de temperatura da linha principal, banho termostático e linha da amônia.

A plataforma de desenvolvimento consiste, especificamente, na montagem e utilização de hardware com características semelhantes às existentes no equipamento MOCVD que se encontra no laboratório de filmes finos no IPEN, permitindo o aproveitamento dos componentes utilizados atualmente.

Para a montagem do sistema, utilizou-se uma placa multifuncional de aquisição de dados USB- $6008^{39}$ apresentada na figura 10 , com as seguintes especificações: 8 entradas analógicas , 2 saídas analógicas , 12 Entradas/Saídas digitais e 1 contador de 32-bits, ligado ao sensor de temperatura (LM35) ${ }^{40}$ e ao amplificador de reles. 


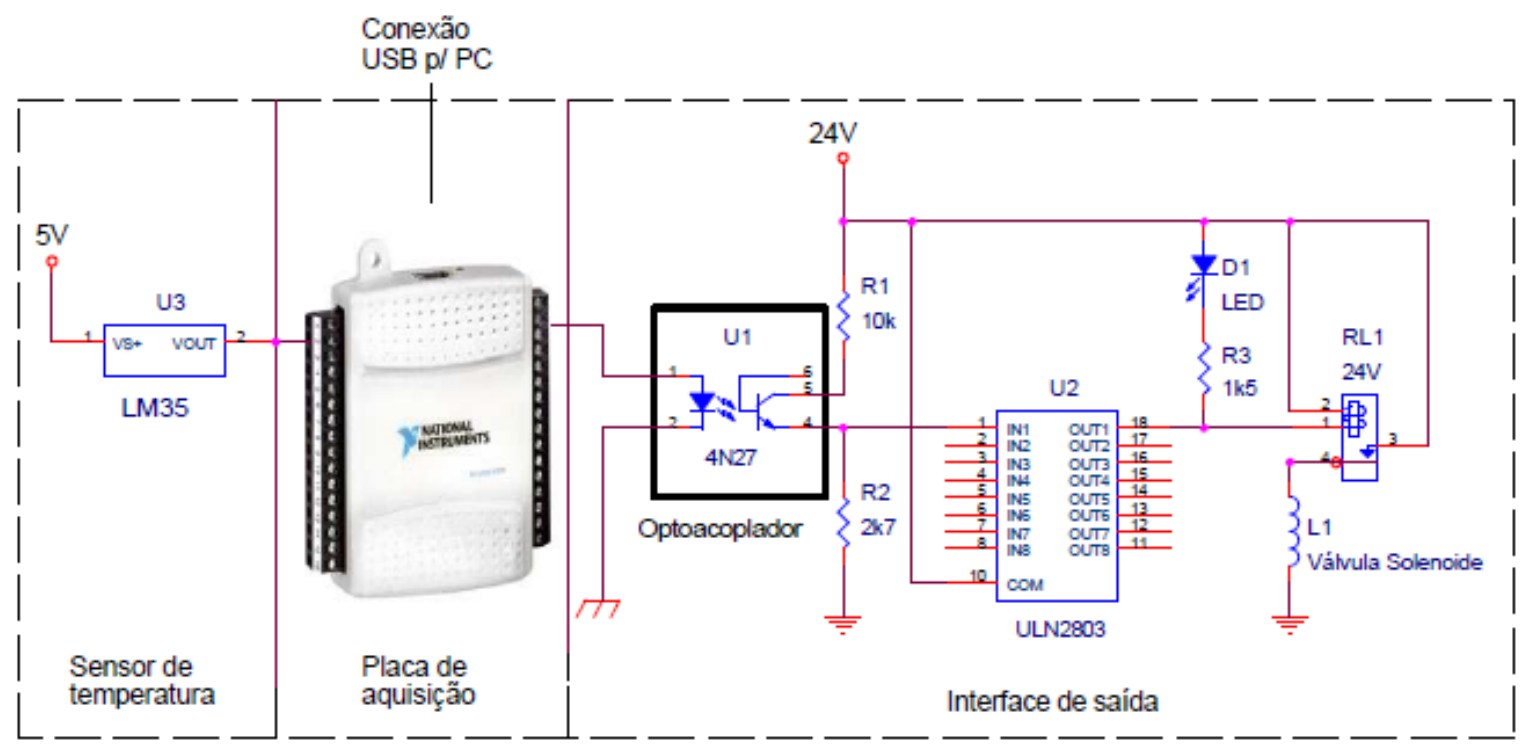

Figura 10: Placa multifuncional de aquisição de dados ${ }^{39} \operatorname{conectada}_{\text {ao }} \operatorname{LM} 5^{40}$ e ao amplificador de reles, para a leitura de um termômetro e o acionamento de um rele.

\subsubsection{Descrição do Circuito}

A saída digital da placa USB-6008 ${ }^{39}$ é do tipo $5 \mathrm{~V}$ (TTL/CMOS) e, para acionar a válvula pneumática (24V) desejada, é necessário um circuito amplificador, mostrado na figura 11.

Foi utilizado um acoplador óptico para a proteção do módulo USB- $6008^{29}$ de um eventual curto-circuito que possa ocorrer na linha de 24V.

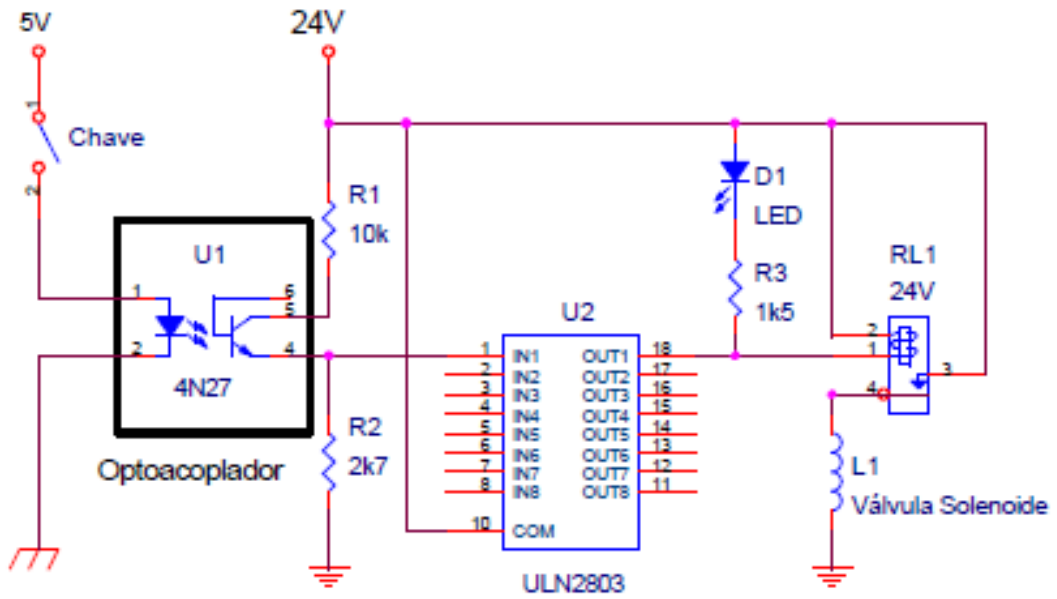

Figura 11: Circuito amplificador utilizado para acionamento das válvulas solenoides 
Para a leitura da temperatura utilizou-se o sensor LM $35^{40}$ mostrado na figura 12. Trata-se de um circuito integrado de medição de temperatura de precisão, cuja tensão de saída é linearmente proporcional à temperatura Celsius (centígrado). Este circuito integrado não necessita de calibração e possui uma faixa de trabalho de -55 a $150^{\circ} \mathrm{C}$ e uma tensão de saída de $10 \mathrm{mV} / \stackrel{\circ}{ } \mathrm{C}$.
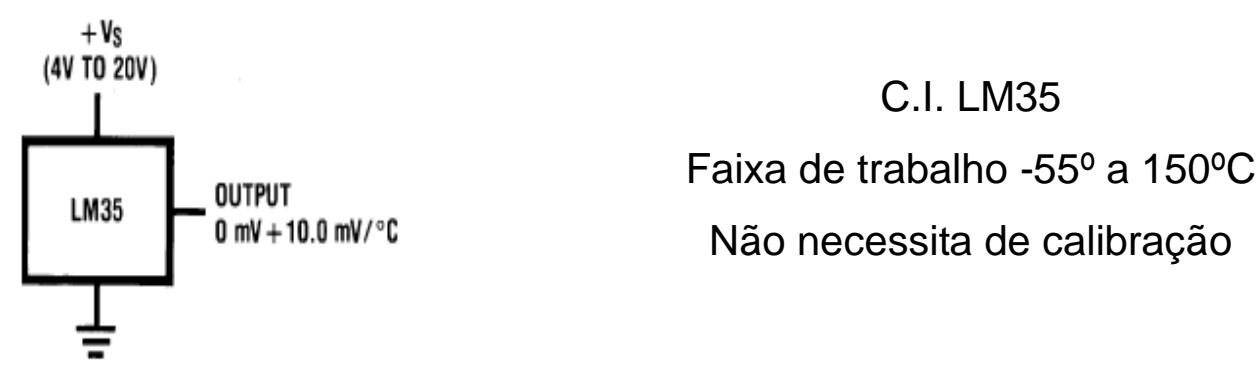

Figura 12: Sensor de temperatura, $\mathrm{LM} 35^{30}$. 


\section{Resultados e Discussão}

A seguir estão apresentados os resultados obtidos após a caracterização dos filmes.

\subsection{Caracterização dos filmes obtidos}

Inicialmente, foram obtidas e caracterizadas amostras de filmes de $\mathrm{TiO}_{2} \mathrm{e}$ de TiN separadamente, a $700 \stackrel{\circ}{\circ}$. Com base na análise dessas amostras foram estipulados os tempos de abertura e fechamento da válvula de admissão de amônia no sistema.

$\mathrm{Na}$ figura 13a está apresentada a superfície do filme de $\mathrm{TiO}_{2}$ obtido após $1 \mathrm{~h}$ a $700^{\circ} \mathrm{C}$. Na figura $13 \mathrm{~b}$ está apresentada a secção transversal do mesmo filme. Observam-se estruturas que crescem perpendicularmente à superfície. A velocidade de crescimento estimada é de $14 \mathrm{~nm} / \mathrm{min}$. Análises por difração de raios- $X$ sugerem a existência das fases anatase e rutilo.

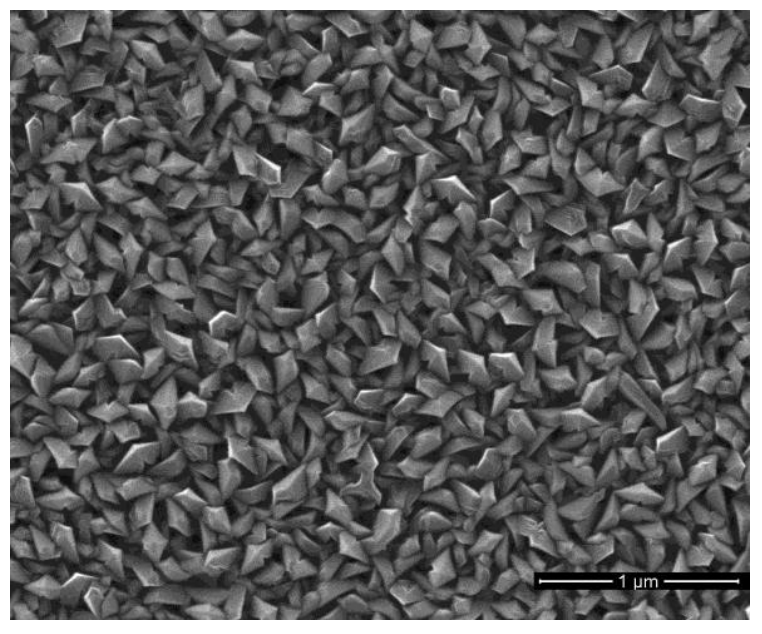

(a)

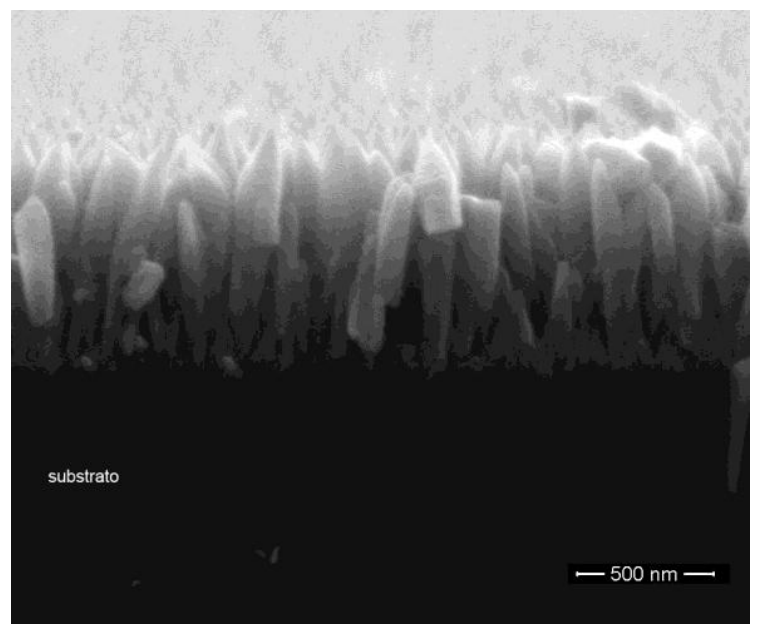

(b)

Figura 13: Filme de $\mathrm{TiO}_{2}$ crescido por $1 \mathrm{~h}$ a $700^{\circ} \mathrm{C}$. (a) superfície; (b) secção transversal. 
Na figura 14 está apresentado o difratograma do filme de $\mathrm{TiO}_{2}$ obtido após 1h a $700^{\circ} \mathrm{C}$, que sugere a presença das fases rutilo e anatase.

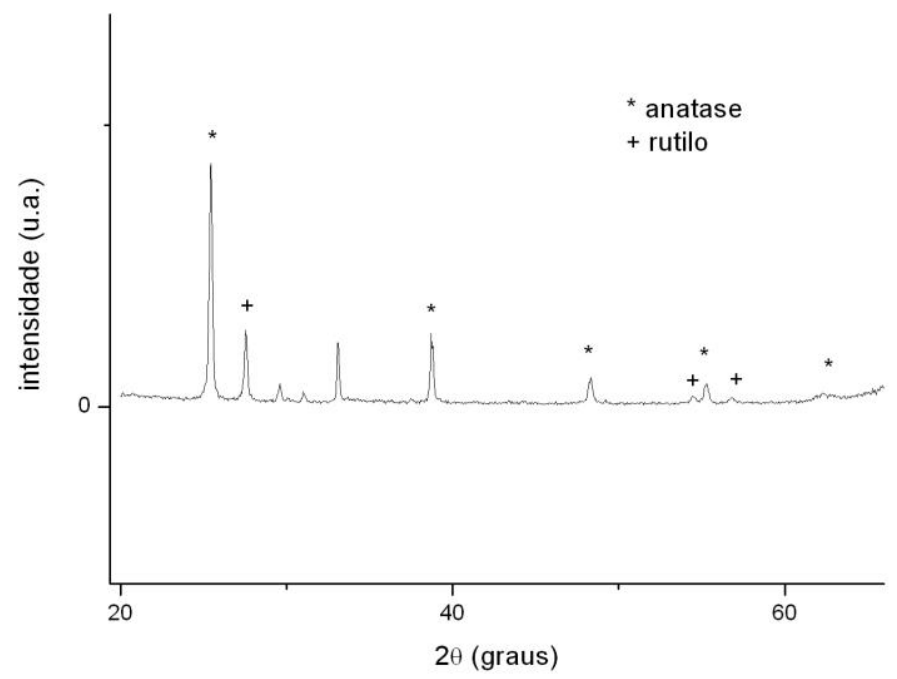

Figura 14: Difratograma do filme de $\mathrm{TiO}_{2}$.

Na figura 15a está apresentada a superfície do filme de TiN obtido após 1h a $700^{\circ} \mathrm{C}$. Na figura $15 \mathrm{~b}$ está apresentada a secção transversal do mesmo filme. Observam-se estruturas que cresceram perpendicularmente à superfície do substrato. A velocidade de crescimento estimada é de $13 \mathrm{~nm} / \mathrm{min}$. Análises por difração de raios- $X$ sugerem a fase TiN.

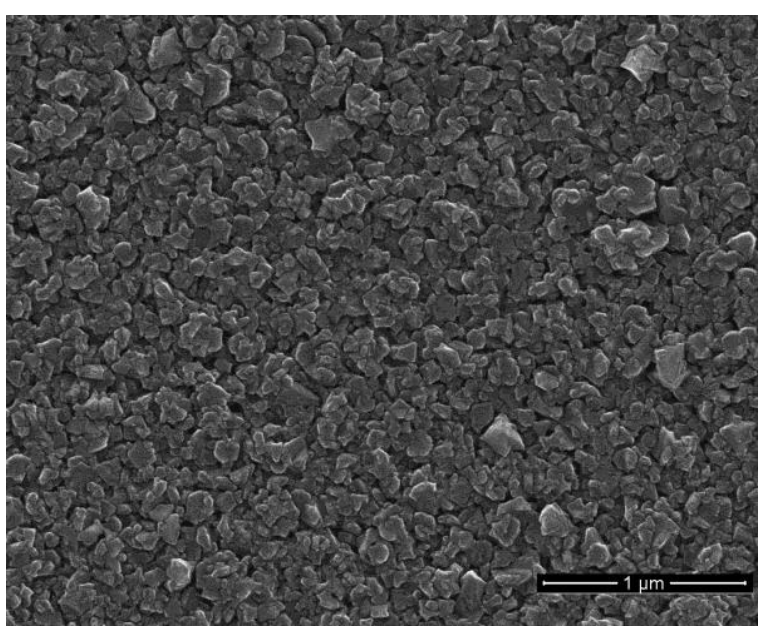

(a)

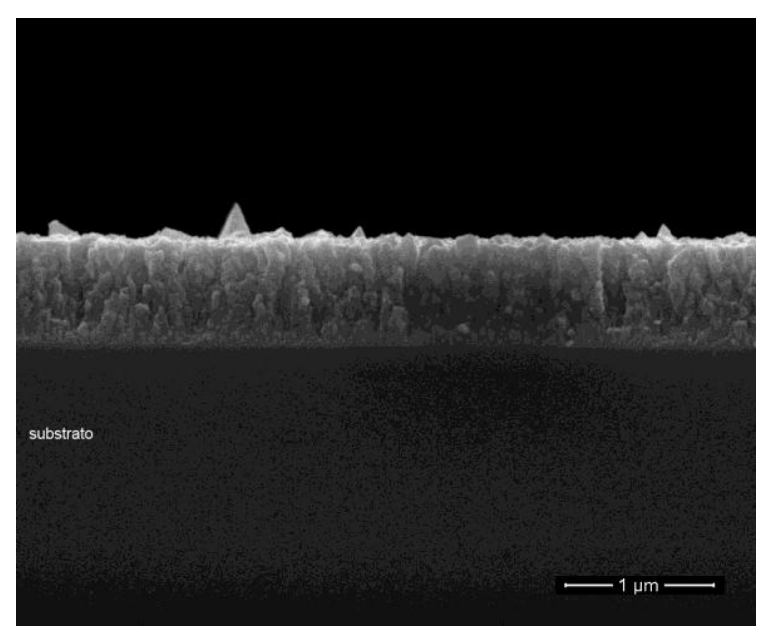

(b)

Figura 15: Filme de TiN crescido por 1h a $700^{\circ} \mathrm{C}$. (a) superfície; (b) secção transversal. 
Na figura 16 está apresentado o difratograma do filme de TiN obtido após 1h a $700^{\circ} \mathrm{C}$.

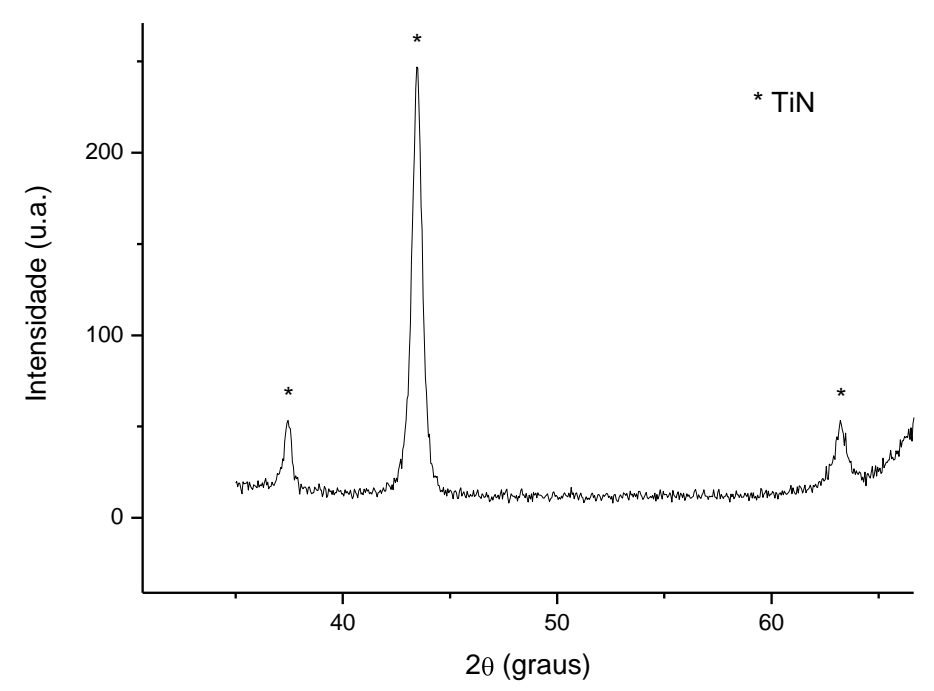

Figura 16: Difratograma do filme de TiN obtido após 1h a $700^{\circ} \mathrm{C}$.

$\mathrm{Na}$ figura 17a está apresentada a superfície do filme composto por multicamadas (4 períodos) $\mathrm{TiO}_{2} / \mathrm{TiN}$ crescido a $700^{\circ} \mathrm{C}$. A figura $17 \mathrm{~b}$ é a secção transversal do mesmo filme em imagem formada por elétrons secundários. Observa-se crescimento colunar. Na figura 17c está apresentada a secção transversal do mesmo filme em imagem formada por elétrons retro-espalhados. Observam-se camadas alternadas de $\mathrm{TiO}_{2}$ e $\mathrm{TiN}$. A espessura do período é de aproximadamente $174 \mathrm{~nm}$.

$\mathrm{Na}$ figura 18a está apresentada a superfície do filme composto por multicamadas (8 períodos) $\mathrm{TiO}_{2} / \mathrm{TiN}$ crescido a $700^{\circ} \mathrm{C}$. A figura $18 \mathrm{~b}$ é a secção transversal do mesmo filme em imagem de elétrons secundários. Observa-se crescimento colunar. Na figura 18c está apresentada à secção transversal do mesmo filme em imagem de elétrons retro-espalhados. Observam-se camadas alternadas de $\mathrm{TiO}_{2}$ e TiN. A espessura das camadas de $\mathrm{TiO}_{2}$ é de aproximadamente $64 \mathrm{~nm}$ e as de TiN são de aproximadamente $20 \mathrm{~nm}$. A espessura total do período é de aproximadamente $84 \mathrm{~nm}$. 


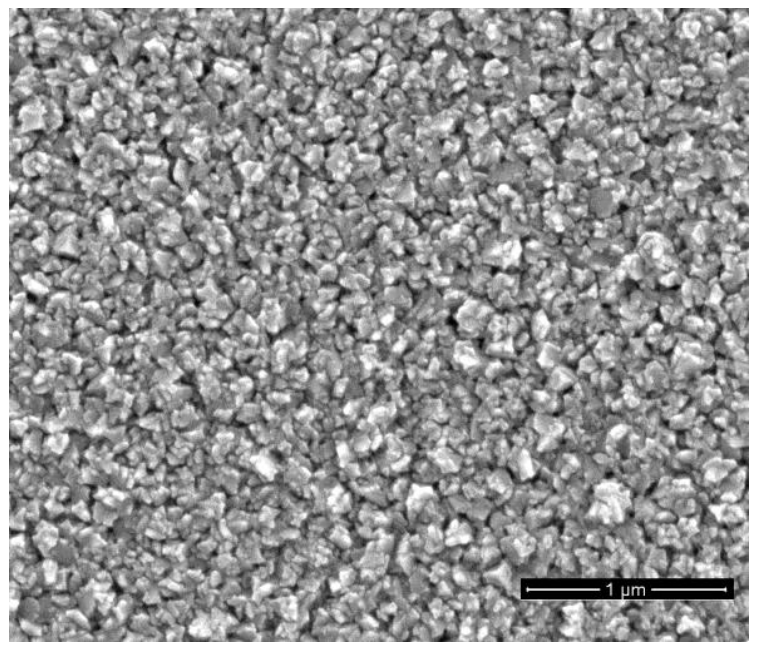

(a)
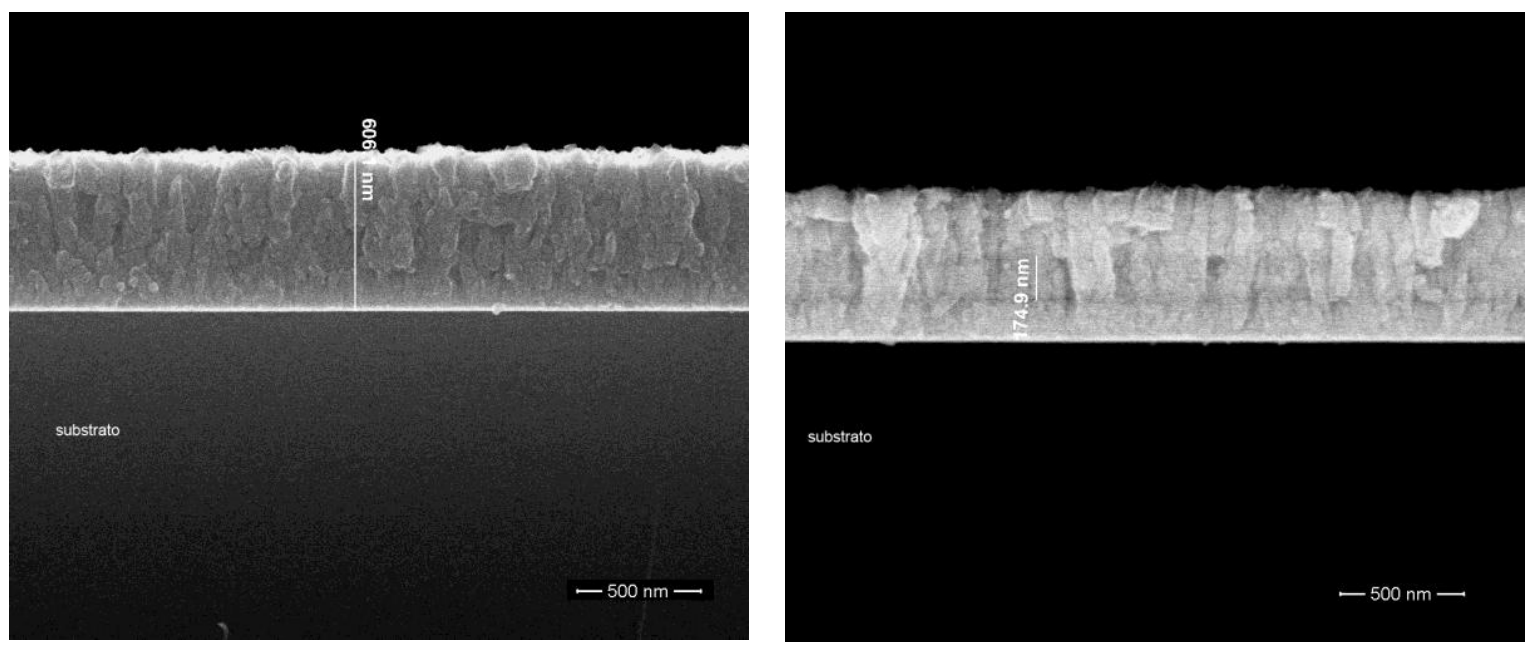

(b)

(c)

Figura 17: Filme composto por multicamadas (4 períodos) $\mathrm{TiO}_{2} / \mathrm{TiN}$ a $700^{\circ} \mathrm{C}$. (a) superfície; (b) secção transversal em imagem de elétrons secundários; (c) secção transversal em imagem de elétrons retro-espalhados. 


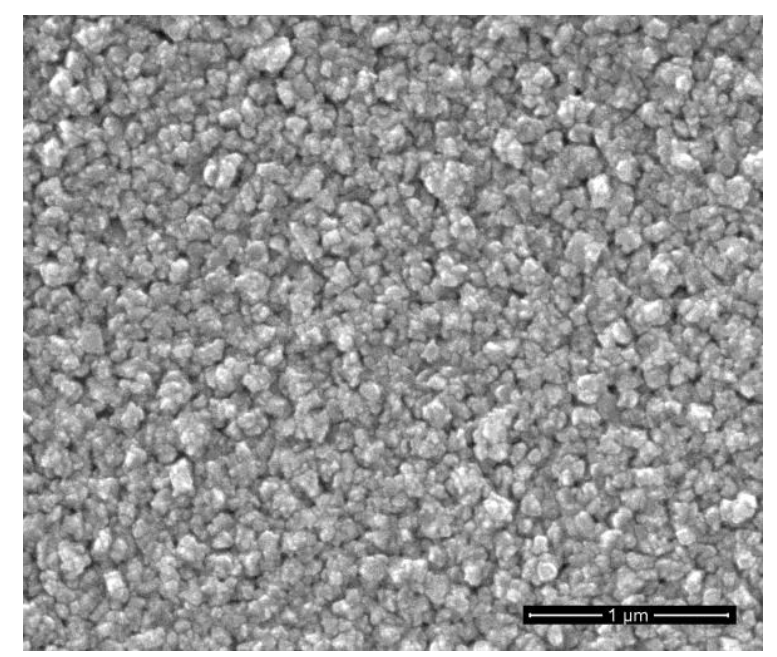

(a)

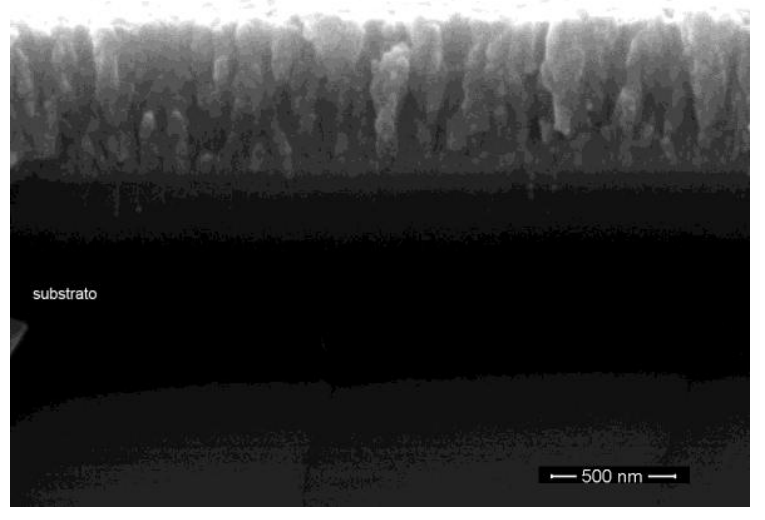

(b)

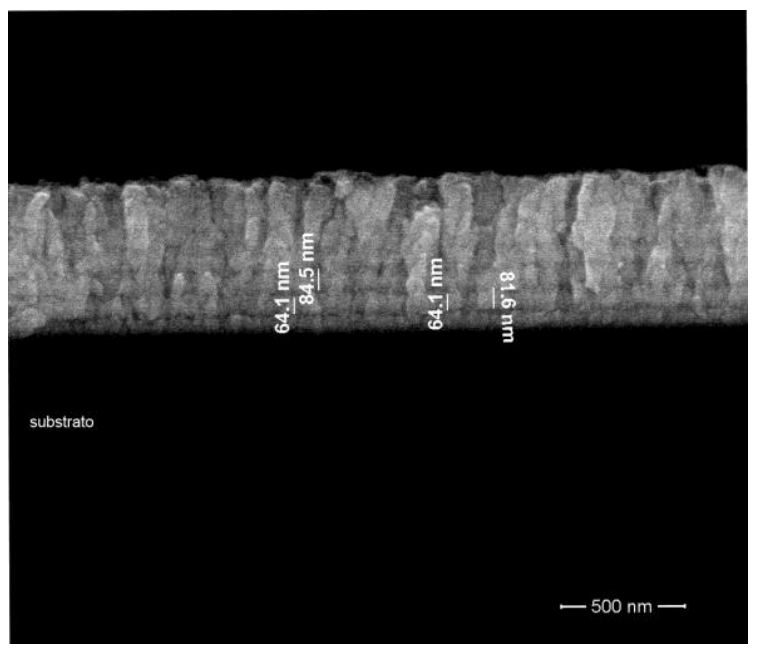

(c)

Figura 18: Filme composto por multicamadas (8 períodos) $\mathrm{TiO}_{2} / \mathrm{TiN}$ a $700^{\circ} \mathrm{C}$. (a) superfície; (b) secção transversal em imagem de elétrons secundários; (c) secção transversal em imagem de elétrons retro-espalhados.

\subsection{Montagem do circuito e simulação do sistema}

O programa do equipamento MOCVD foi desenvolvido para a plataforma Microsoft Windows ${ }^{\circledR}$ 95/98/NT/2000/XP/VISTA. O compilador depurador de código usado é a ferramenta ANSI C Labwindows/CVI da National Instruments, com um ambiente de desenvolvimento que possui um abrangente conjunto de ferramentas de programação para a criação de testes e aplicações em controle.

O programa está dividido em duas partes, onde uma é um arquivo em formato texto com os parâmetros do ciclo de teste e a outra com a rotina principal. 
O circuito experimental de acionamento das válvulas foi montado em uma placa de circuito impressa tipo "universal" e condicionado em uma caixa plástica, conforme mostrado nas figuras 19 e 20.

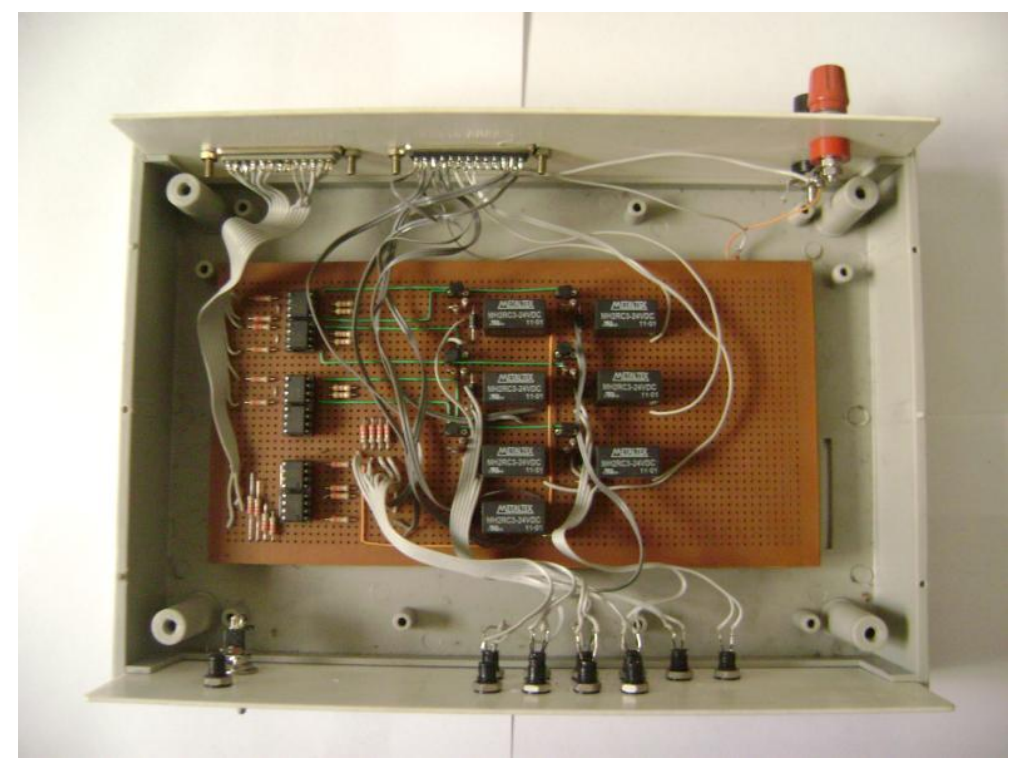

Figura 19: Montagem experimental do circuito.

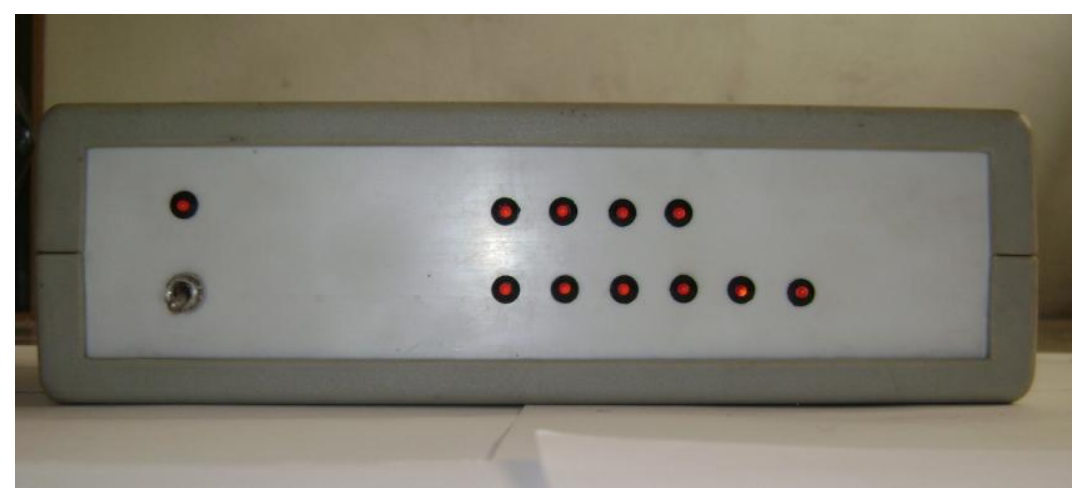

Figura 20: Vista frontal, led's indicadores visuais de acionamento.

\subsubsection{Simulação do sistema de controle}

Foram realizados testes de simulação em bancada no circuito de acionamento das válvulas, leitura do fluxo de massa, leitura e controle das temperaturas.

O programa ficou rodando em "vazio" com ciclos de recobrimento diferentes. Os resultados foram satisfatórios e a implementação da automação do processo eliminará "a variável" operador na resposta do experimento, bem como permitirá a abertura e fechamento das válvulas em tempos menores. Dessa 
forma, será possível crescer filmes multicamadas com espessuras da ordem de alguns nanômetros.

\subsubsection{Arquivo de parâmetros de teste}

Como mostra a figura 21, o arquivo com os parâmetros de teste contém as variáveis dos parâmetros de processo, tais como, tempo do ciclo de recobrimento, tempo de acionamento das válvulas e eventos ligado/desligado das válvulas, que são definidos em um arquivo no formato texto.

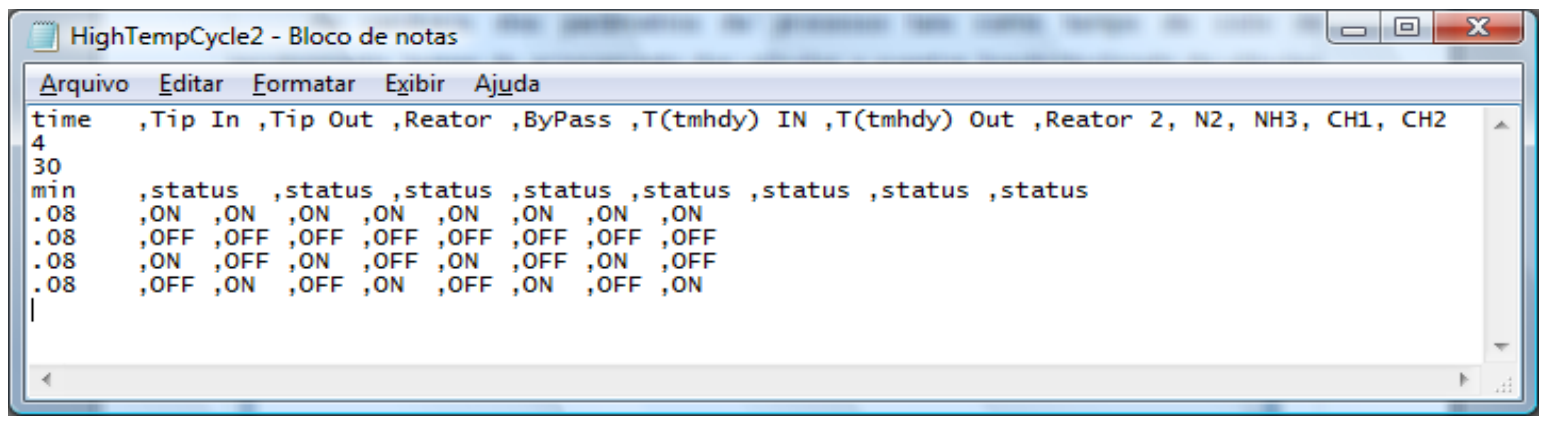

Figura 21: Arquivo com os parâmetros de teste.

Descrição das linhas:

- Na primeira linha: nome das respectivas válvulas.

- Na segunda: quantidade de passos a serem executados.

- Na terceira linha: tempo total do ciclo em minutos.

- Na quarta linha: tempo e "status" das válvulas.

- A partir da quinta linha: tempo (em fração de minutos) e estado das válvulas ligado/desligado

\subsection{Programa, Rotina Principal}

O programa denominado MOCVD.Exe contém a rotina principal (Main_IPEN.c) que faz a leitura do arquivo com os parâmetros de teste e inicia o processo de controle do equipamento. Após carregar o programa e, ao pressionar o botão "Inicio", entra em execução a função IPEN_Teste. 
A função IPEN_Teste executa os acionamentos das válvulas conforme estabelecido no arquivo parâmetros de teste.

Ao final do ciclo todas as válvulas são desligadas.

\subsection{Descrição da Interface de usuário}

Na figura 22, está disposta a tela principal com caixas de texto, botões e indicadores visuais demonstrando o status do ciclo de recobrimento. As figuras 23 a 31 descrevem os itens da tela principal.

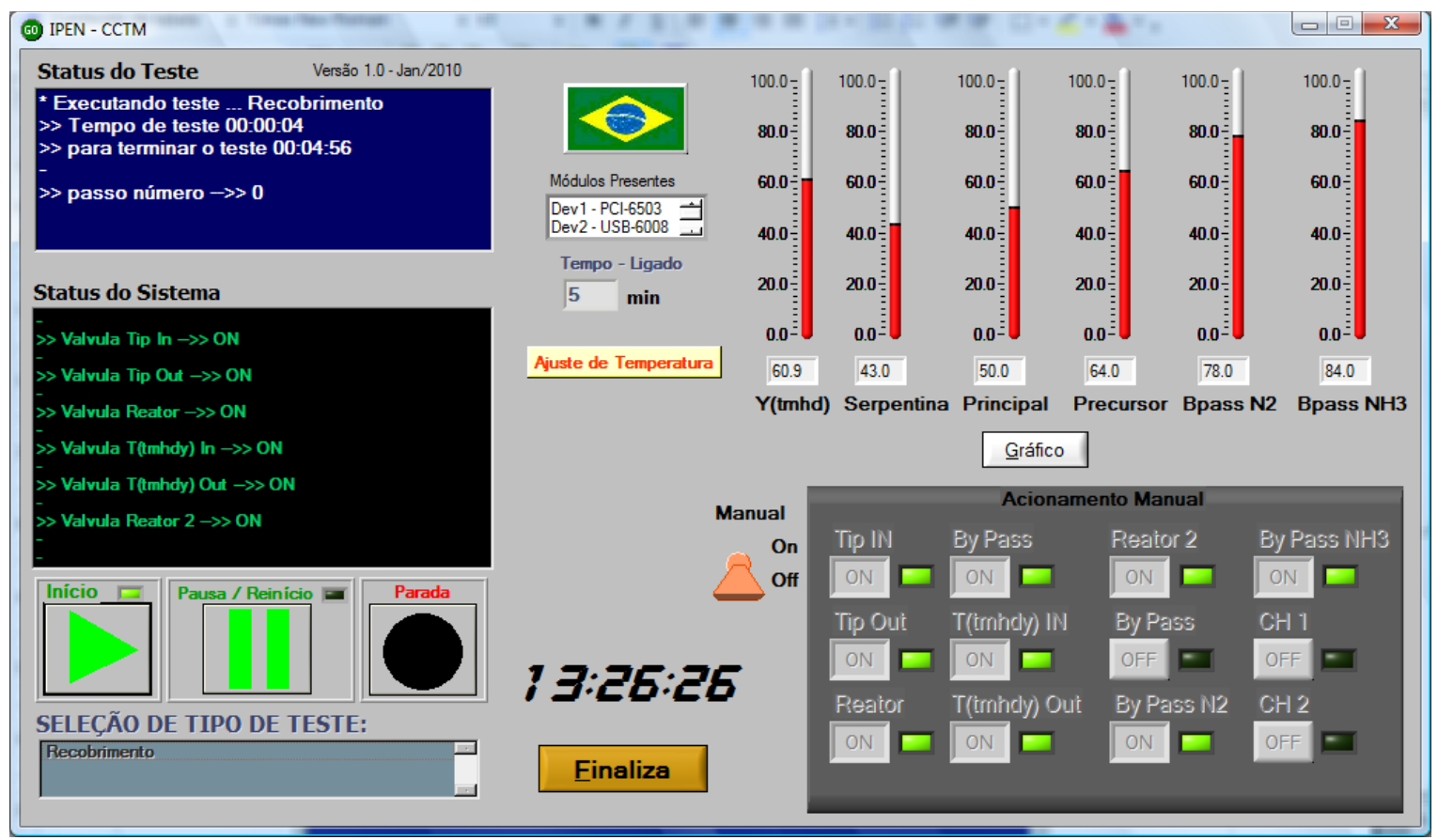

Figura 22: Tela principal, interface do usuário.

A figura 23 mostra a caixa de texto com o status do teste. Esta tela indica o tempo de teste, ou seja, quanto tempo faz que o ciclo começou, quanto tempo falta para terminar o ciclo de teste, e passo em execução, ou seja, qual item a partir da linha cinco está sendo executado. 


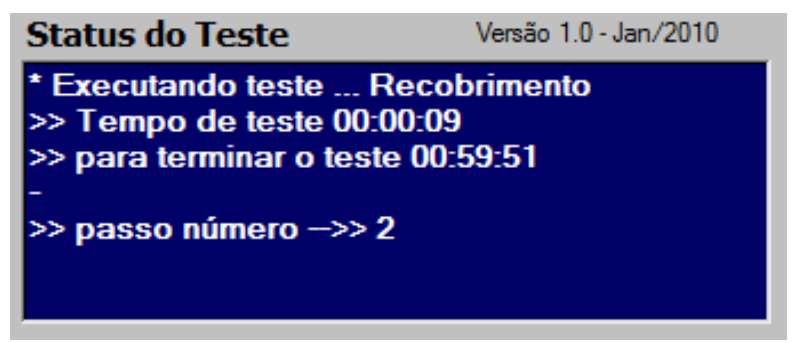

Figura 23: Status de teste.

A figura 24 mostra a caixa de texto com o status do sistema. Esta tela indica quais válvulas estão acionadas no decorrer da execução do programa.

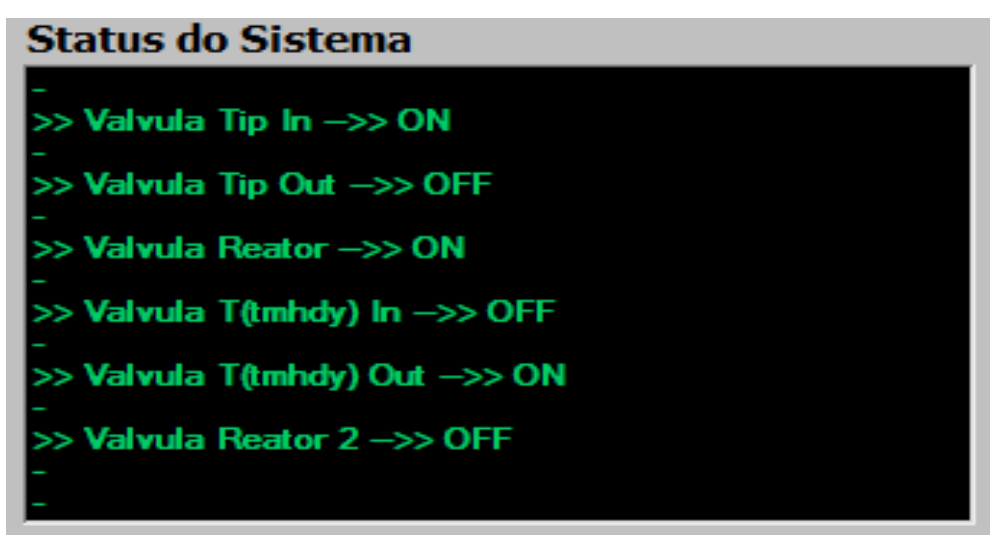

Figura 24: Status do sistema.

Na figura 25 está apresentada a tela que indica a temperatura das linhas dos gases. A leitura das temperaturas é feita mesmo sem iniciar o ciclo de recobrimento. A figura 26 mostra um gráfico de acompanhamento da variação das temperaturas. 


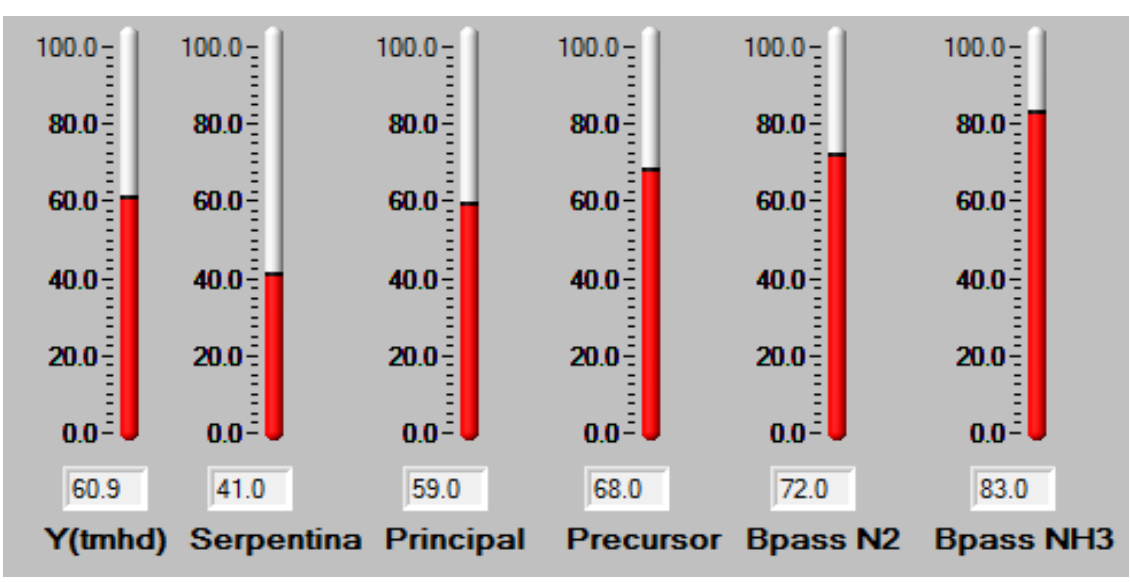

Figura 25: Indicação da temperatura da linha dos gases.

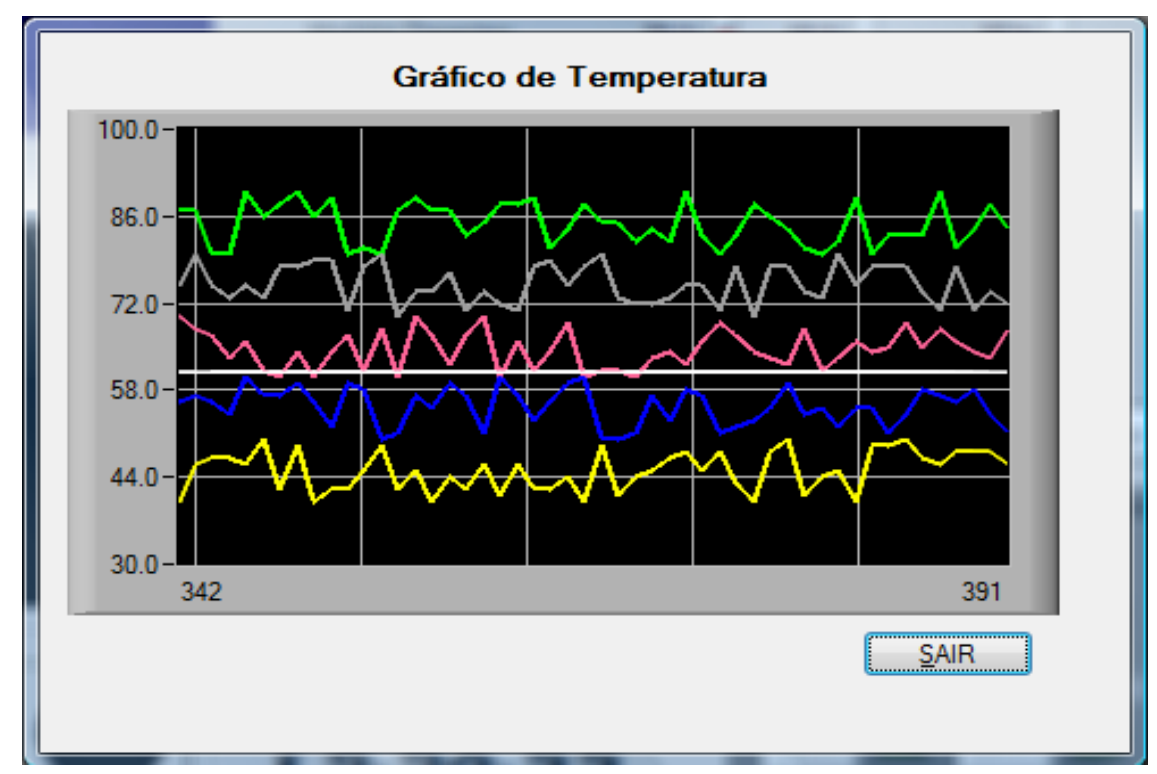

Figura 26: Gráfico de acompanhamento da variação das temperaturas. Opção selecionada pelo botão "Gráfico"

A figura 27 mostra a tela com os botões de início do ciclo, pausa e finalização do ciclo. Quando o botão pausa for pressionado a indicação visual acima do botão ficará piscando, a contagem do ciclo será interrompida e o sistema manterá a atual condição de acionamento das válvulas. Quando o botão pausa for pressionado novamente, a indicação visual acima do botão irá se apagar e a contagem do ciclo continuará. 


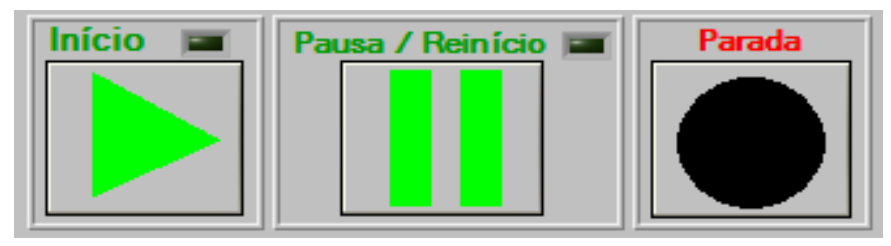

Figura 27: Botões de Inicio, pausa, parada do teste.

A figura 28 mostra a tela com os botões de acionamento manual. Estes botões são utilizados para acionar as válvulas individualmente numa eventual manutenção do sistema, bem como para o ajuste de fluxo dos gases em um "setup" inicial do processo.

Durante a execução do ciclo de revestimento, o operador poderá colocar em modo manual e ligar/desligar qualquer válvula do sistema. Entretanto, quando outro passo entrar em vigor, o estado da válvula irá agir conforme determinado no novo passo.

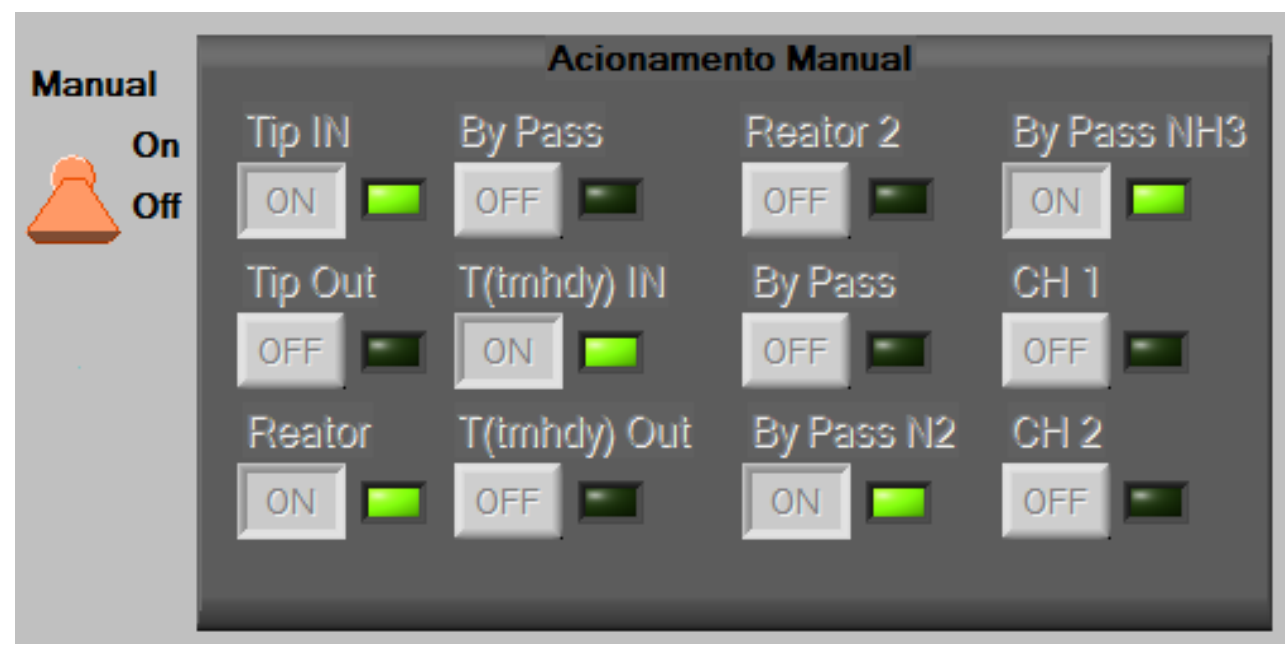

Figura 28: Botões de acionamento manual das válvulas.

A figura 29 mostra a caixa de texto com o nome do teste, neste caso "Recobrimento". O operador poderá ter vários testes com "setups" diferentes e nomeá-los diferentemente. 


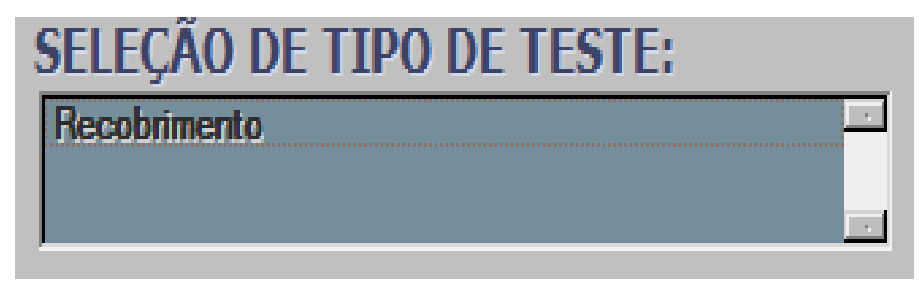

Figura 29: Seleção do teste

A figura 30 mostra a tela principal com o botão de temperatura. Este botão dá acesso à outra tela, conforme descrito na figura 31, com os valores mínimo e máximo da temperatura de cada linha. A temperatura das linhas poderá ser ajustada individualmente antes ou durante o processo de recobrimento. A figura 32 mostra o arquivo "Templimites.txt" com a configuração inicial das temperaturas.

\section{Ajuste de Temperatura}

Figura 30: Ajuste de temperatura individual.

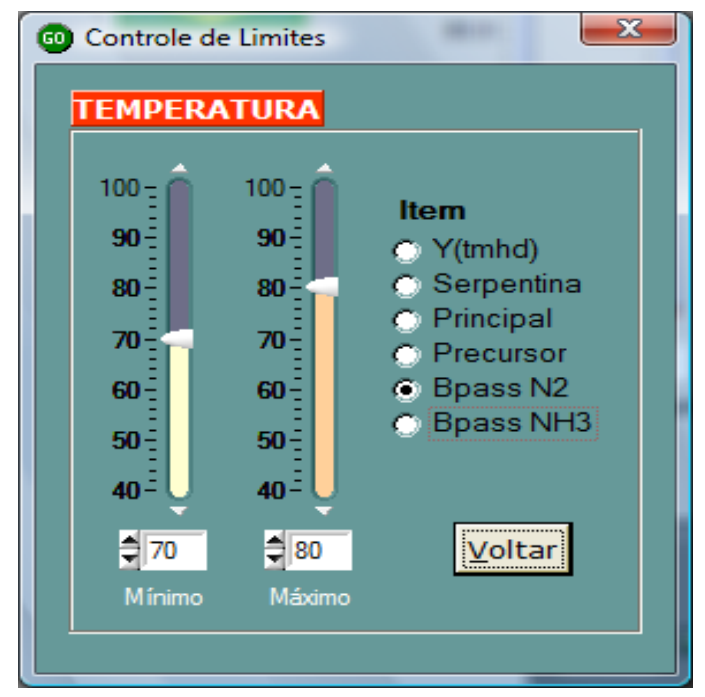

(20)

Figura 31: Botão de ajuste de temperatura. 


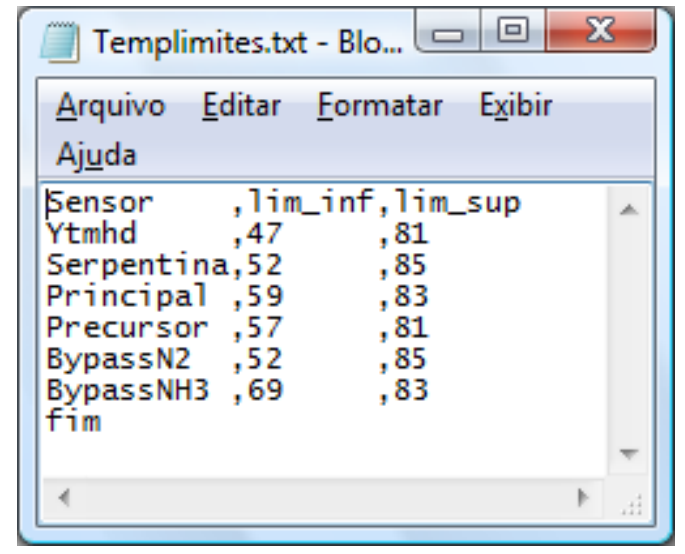

Figura 32: Arquivo "Templimites.txt" com setup das temperaturas.

\subsection{Fluxograma geral do programa}

Na figura 33 é mostrado o fluxograma geral do programa. Nota-se que após cada evento a temperatura é atualizada na tela. 


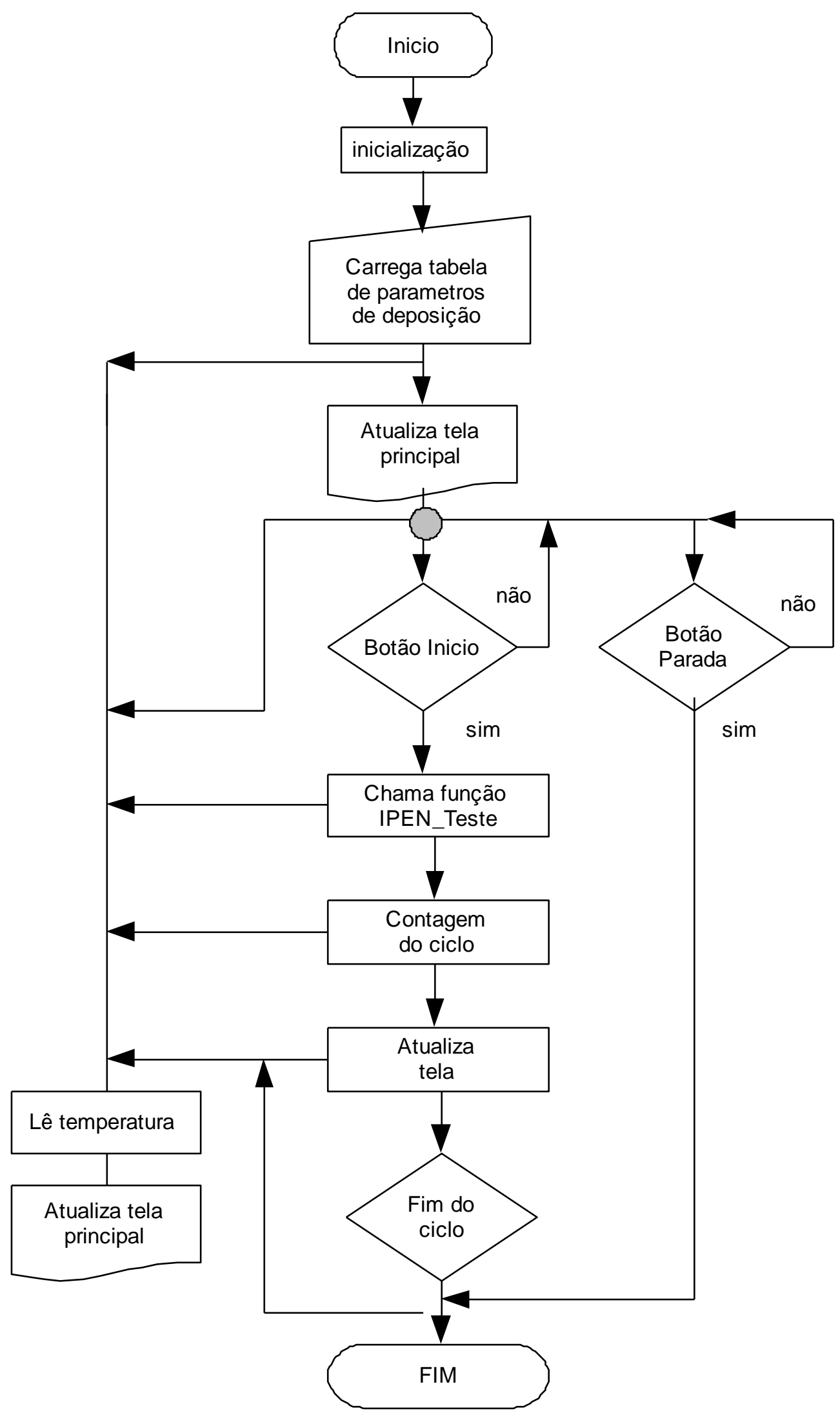

Figura 33: Fluxograma geral do programa 


\subsubsection{Fluxograma das chamada de funções do programa}

Na figura 34 é mostrada a rotina principal do programa. A rotina Main gerencia toda a execução do programa. Os retângulos representam as funções criadas para o controle do processo. As demais são as palavras reservadas (funções internas) do compilador Labwindows/CVI.

Descrição das funções nos retângulos:

- Inicialização: Faz a leitura dos arquivos Templimites.txt e o arquivo com os parâmetros de teste, configura a placa de aquisição USB-6008 de forma que todas as válvulas fiquem em seu estado inicial e configura a leitura das temperaturas.

- RelogioTempoTeste: Inicializa o tempo de teste em execução.

- RelogioTempoTesteRestante: Inicializa quanto tempo falta para terminar o teste.

- DisplayCiclo: Contador de passos

- DisplayTesteSelecionado: Mostra na tela o nome do teste em execução 


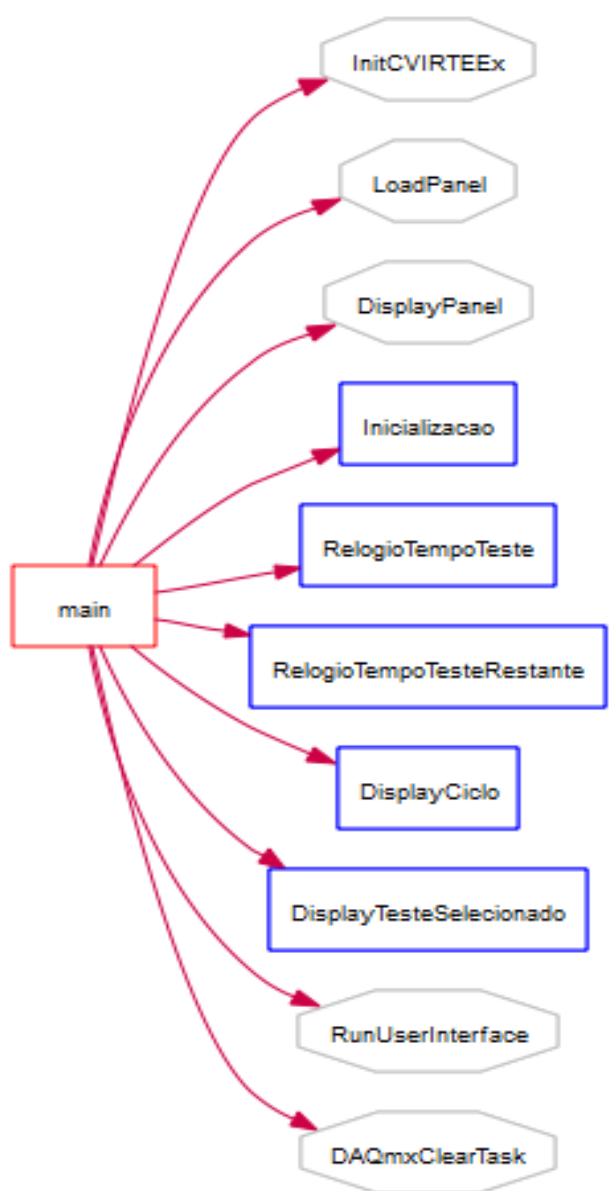

Figura 34: Rotina principal (main_ipen.c).

Na figura 35 é mostrada com maiores detalhes a função Inicialização. Outro objetivo desta função é a de configurar a "Thread" (uma forma de executar duas ou mais tarefas ao mesmo tempo) que gerencia a leitura das temperaturas. 


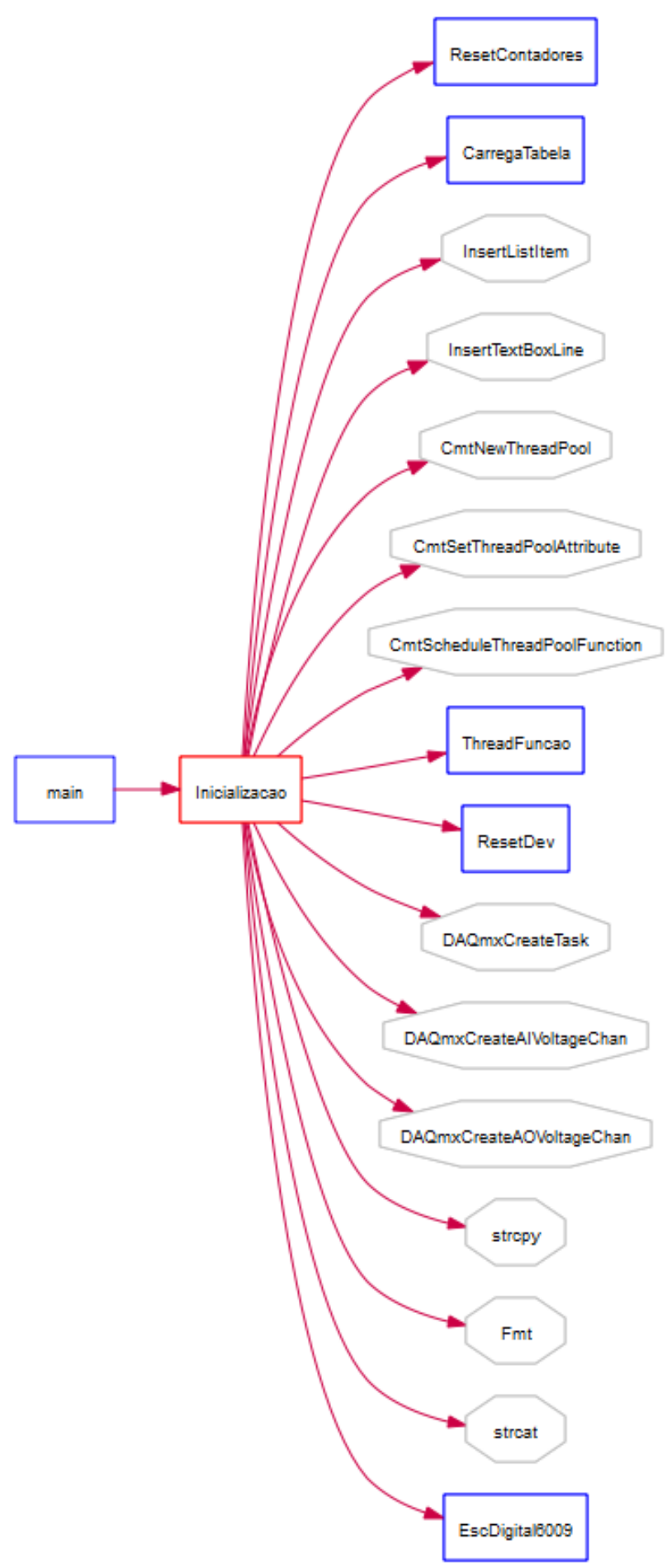

Figura 35: Inicialização: Lê tabela de parâmetros, inicializa placas, desliga reles e habilita leitura de temperatura. 


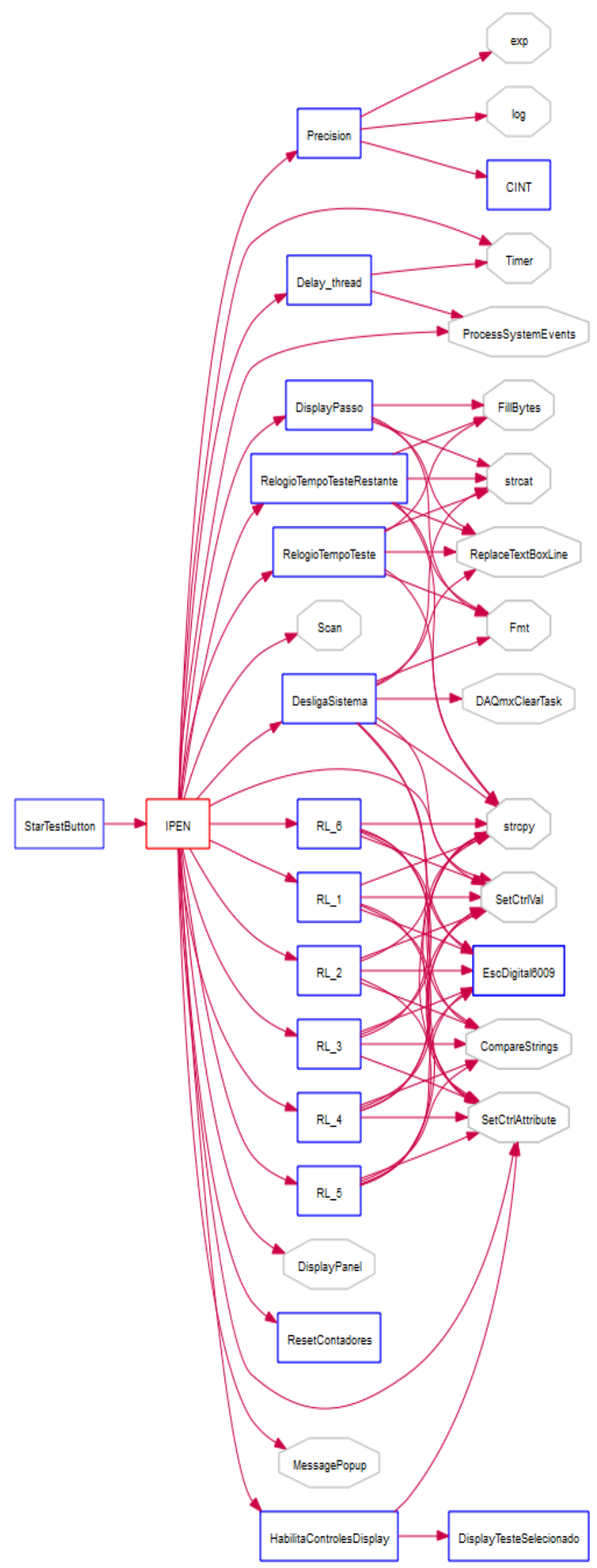

Figura 36: Função IPEN_Teste: Após pressionar o botão "Inicio", ocorre o controle do ciclo térmico. 
Na figura 36 é mostrada a função IPEN_Teste, que contém um conjunto de instruções que controla a seqüência de processos que o programa faz durante o ciclo de revestimento.

Na figura 37 é mostrada a seqüência de processos que o programa faz para ler a tabela de parâmetros do ciclo de teste.

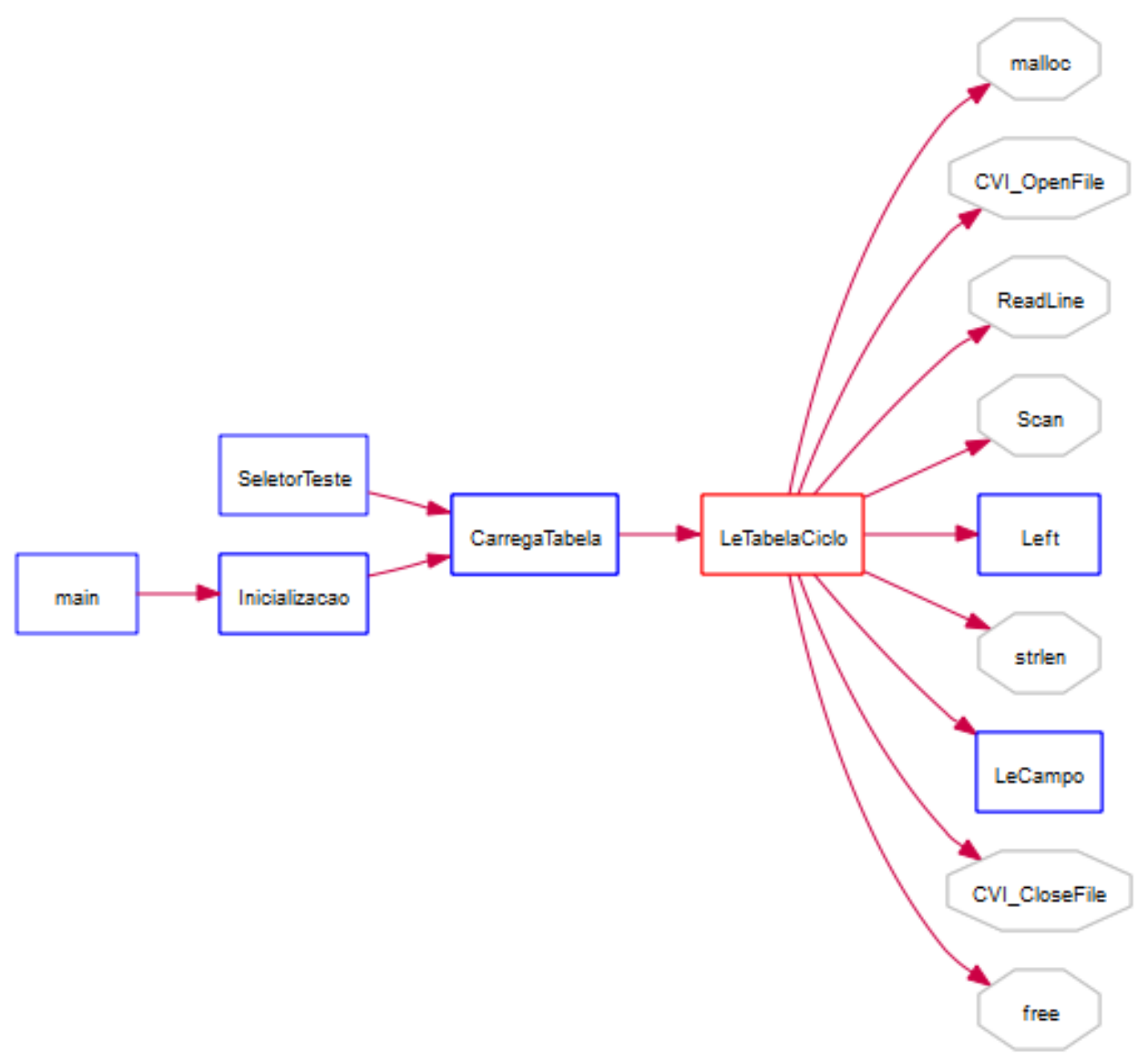

Figura 37: Função: Leitura da tabela de parâmetros e alocação na memória.

Na figura 38 é mostrada a função $R L \_n, A$ função $R L \_n$, que está atrelada a um botão do painel manual que liga/desliga uma válvula. 


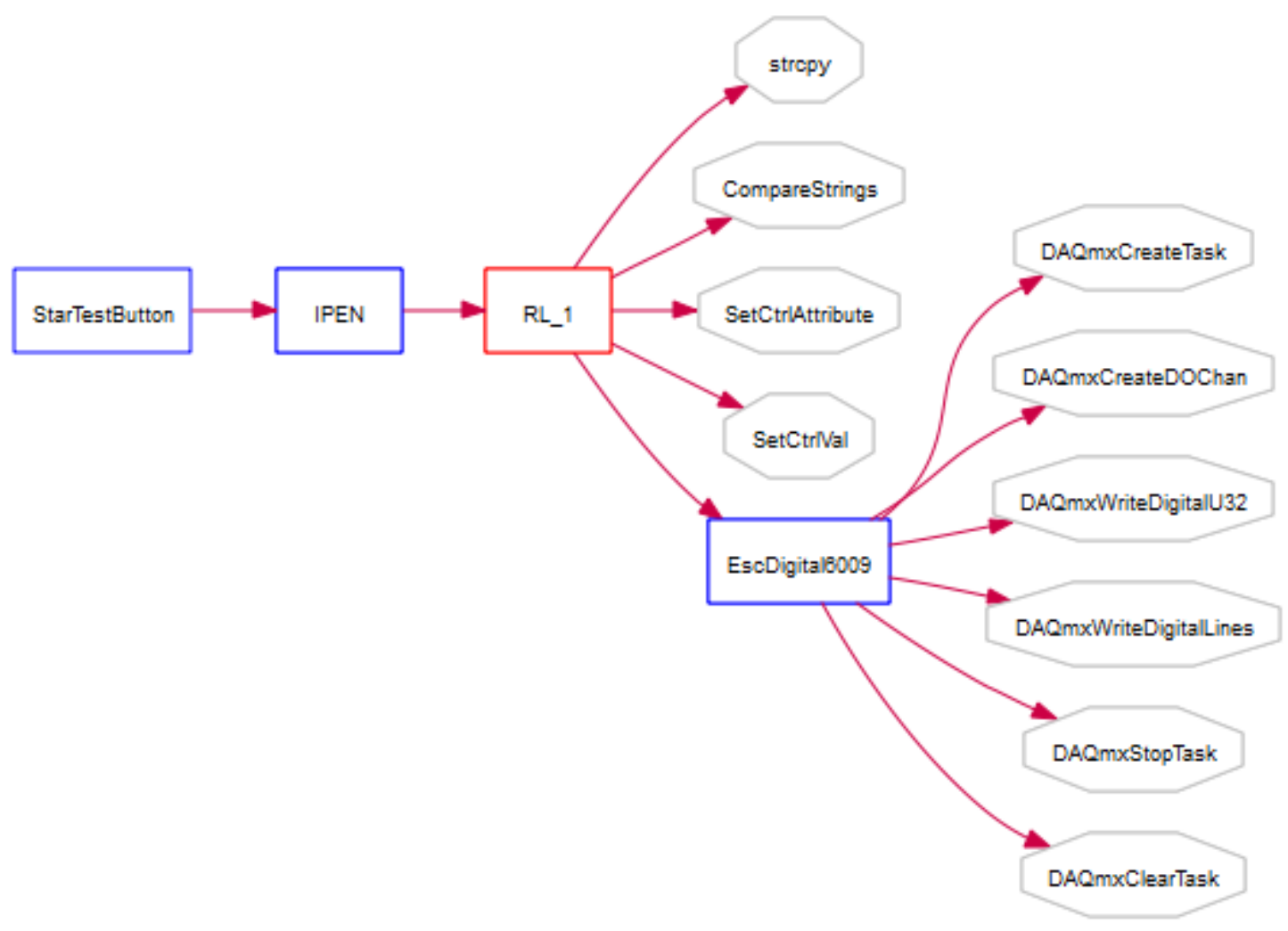

Figura 38: Subrotina RL_n: Botão/função que liga/desliga reles

A figura 39 mostra como está disponibilizada a função EscDigital6008, detentora do controle da placa de aquisição USB-6008. 


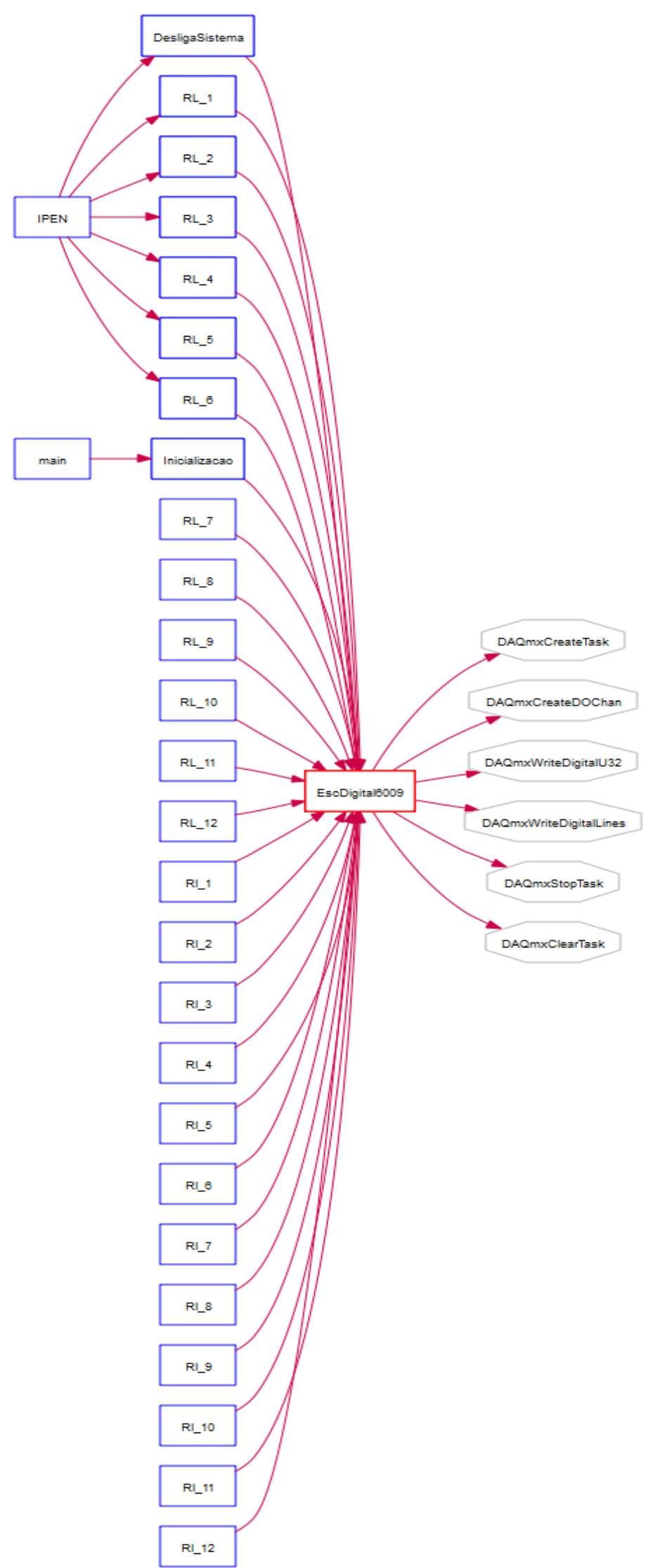

Figura 39: Subrotina EscDigital6008: Acesso a saídas. 
A figura 40 mostra como está disponibilizada a função ThreadFunção, detentora da leitura das temperaturas.

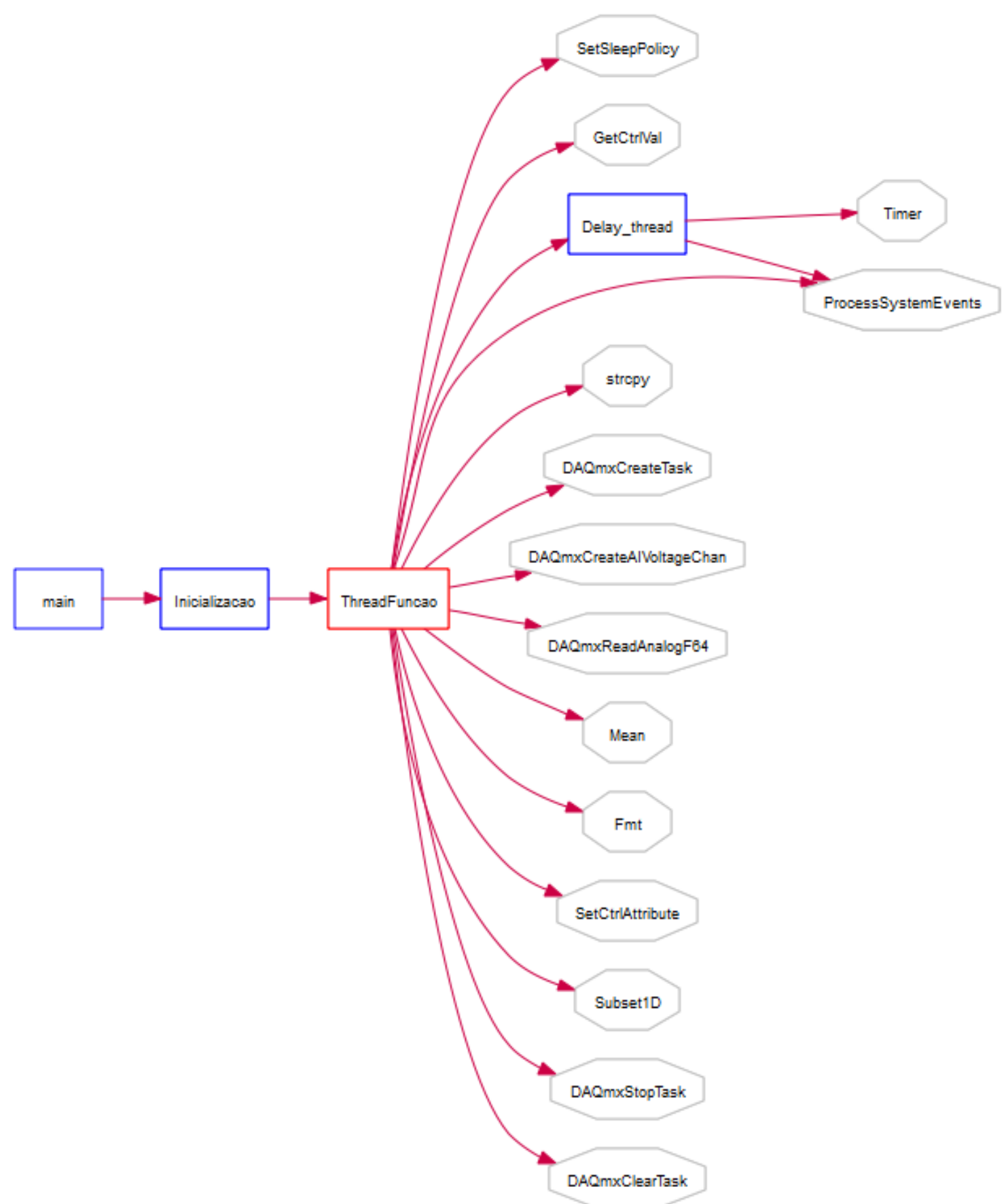

Figura 40: Subrotina ThreadFunção: Faz a leitura/controle das temperaturas e fluxo de massa. 


\section{Conclusões}

1) É possível crescer filmes com estrutura de multicamadas $\mathrm{TiO}_{2} / \mathrm{TiN}$ no equipamento MOCVD disponível no IPEN, em uma única etapa.

2) Os filmes apresentaram crescimento colunar, perpendicular ao substrato. A velocidade de crescimento dos filmes de óxido e de nitreto são similares nas condições estudadas, da ordem de 13-14 nm/min.

3) Durante o experimento, observou-se que a habilidade do operador em abrir e fechar a válvula de amônia nos intervalos utilizados influenciava a espessura de bi-camada dos filmes. Para eliminar a influência do operador nesse procedimento de abertura e fechamento, foi proposto um sistema computadorizado para controlar e monitorar todo o ciclo de deposição dos filmes finos.

4) $O$ modelo proposto foi montado em bancada. Obteve-se bom desempenho nos testes de acionamento das válvulas solenóides, monitoramento da temperatura das linhas dos gases, e seleção de outras opções de tempos de crescimento. 


\section{REFERÊNCIAS BIBLIOGRÁFICAS}

1 D.G.TEER, Evaporation and Sputter Techniques in: Coatings for high temperature applications. E.Lang (Eds.) Elsevier Applied Science Publishers, 1986.

2 POCHET, L.F.; HAVARD, P.; SAFAIE, S. CVD coatings: from cutting tools to aerospace applications and its future potential, Surf. Coat. Technol, v. 94-95, p. $70-75,1997$.

3 I.G. BROWN, A.; ANDERS, M.R.; DICKINSON, R.A.; MACGILL, O.R. Monteiro Surf. Coat. Technol. v. 112, n.1-3, p. 271277, 1999.

4 PRZYBYLSKI, K.; YUREK, G.J. The Influence of Implanted Yttrium on the Microstructures of Chromia Scales Formed on a Co-45 Weight Percent $\mathrm{Cr}$ Alloy. J. Electrochem. Soc. v. 135, n. 2, p. 517-523, 1988.

5 M.H. LI; X.F. SUN; J.G. LI; Z.Y. ZHANG; T. JIN; H.R. GUAN; Z.Q. HU Oxidation behavior of sputter-deposited NiCrAlY coating, Surf. Coat. Technol. v. 165, n. 3, p. 241247, 2003.

6 F.J. PÉREZ,; M.P. HIERRO,; F. PEDRAZA,; C. GÓMEZ,; M.C. CARPINTERO,; J.A. TRILLEROS, Adhesion properties of aluminide coatings deposited via CVD in fluidised bed reactors (CVD-FBR) on AISI 304 stainless steel, Surf. Coat. Technol, v. 133-134, p. 338-343, 2000.

7 BONNET, G. The effect of rare earths deposited on steel surfaces, by different processes (sol/gel, electrophoresis, OMCVD), on high temperature corrosion behaviour, Corrosion Science, v. 35, n. 5-8, p. 893-899, 1993.

8 BONNET, G.; LACHKAR, M.; COLSON, J.C.; LARPIN, J.P. Characterization of thin solid films of rare earth oxides formed by the metallo-organic chemical 
vapour deposition technique, for high temperature corrosion applications, Thin Solid Films, v. 261, p. 31-36, 1995.

9 TJONG, S.C.; CHEN, H. Nanocrystalline materials and coatings. Mat. Sci. Eng, v. 45, n.1-2, p.1-88, 2004.

10 LIU W.; CHUNG C.H.; MIAO C.Q.; XIE Y.H. Chemical vapor deposition of large area few layer graphene on $\mathrm{Si}$ catalyzed with nickel films. Thin solid films. v. 518, n. 6, p. 128-132, 2010.

11 Y. MAKINO; M. NOSE; T. TANAKA; M. MISAWA; A. Tanimoto; T. Nakai; K. Kato; K. Nogi Characterization of Ti(NxOy) coatings produced by the arc ion plating method Surf. Coat. Technol. v.98,n. 1-3, p. 934-938, 1998.

12 TING, C. Y. TiN as a high temperature diffusion barrier for arsenic and boron. Thin Solid Films, v. 119, p. 11-21, 1984.

13 OYAMA, T; OHSAKI, H.; TACHIBANA, Y.; HAYASHI, Y.; ONO, Y.; HORIE, N. A new layer system of anti-reflective coating for cathode ray tubes. Thin Solid Films, v. 1-2, n. 351, p. 235-240, 1999.

14 F. FABREGUETTE; L. IMHOFF; O. HEINTZ; M. MAGLIONE; B. DOMENICHINI; M. C. MARCO DE LUCAS; P. SIBILLOT; S. BOURGEOIS; M. SACILOTTI Structural and in depth characterization of newly designed conducting/insulating $\mathrm{TiN}_{\mathrm{x}} \mathrm{O}_{\mathrm{y}} / \mathrm{TiO}_{2}$ multilayers obtained by one step LP-MOCVD growth, Applied Surface Science, v. 175-176, p. 685-690, 2001.

15 SILVA, HILGAD MONTELO DA Simulação com hardware in the loop aplicada a veículos submarinos semi-autônomos. 2008. Dissertação (Mestrado) - Universidade de São Paulo, São Paulo.

16 PIERSON, H.O. Handbook of Chemical Vapor Deposition (CVD), 2ed, Noyes Publications, William Andrew Publishing, LLC, New York, USA, 1999. 
17 SINGH, M.P.; SHIVASTRANKAR, S.A. Low-pressure MOCVD of $\mathrm{Al}_{2} \mathrm{O}_{3}$ films using aluminium acetylacetonate as precursor: Nucleation and growth, Surf. Coat. Technol, v. 161, n. 2-3, p. 135-143, 2002.

18 XING, G. ; ZHEN, Y. Z. State key lab of silicon materials, Zhejiang University, China.P.R, Journal of Microwaves and Optoelectronics, v. 2, n. 5, 2002.

19 BATTISTON, G. A.; GERBASI, R. ; PORCHIA, M Influence of substrate on structural properties of $\mathrm{TiO}_{2}$ thin films obtained via MOCVD, Thin Solid Films, v. 239, p. 186-191, 1994.

20 WICAKSANA, D.; KOBAYASHI, A. ; KINBARA, A. Process effects on structural properties of $\mathrm{TiO}_{2}$ thin films by reactive sputtering, J. Vac. Sci. Technol. v. 10, n.4, p. 1479-1482, 1992.

21 KIM, S. H.; PARK, H.; LEE, K. H.; JEE, S. H.; KIM, D.; YOON, Y. S.; CHA, H. B. Structure and mechanical properties of titanium nitride thin films grown by reactive pulsed laser deposition, J. Ceramic Process. Research. v. 10, n. 1, p. 49-53, 2009.

22 MENDIBIDE, C.; STEYER, P.; FONTAINE, J.; GOUDEAU, P. Improvement of the tribological behavior of PVD nanostratified TiN/CrN coatings An explanation. Surface and Coatings Technology, v. 201, n. 7-20, p. 41194124, 2006.

23 XU, J.; HATTORI, K.; SEINO, Y.; KOJIMA, I. Microstructure and properties of CrN/Si3N4 nano-structured multilayer films. Thin Solid Films, v. 414, n. 2-22, p. 239-245, 2002.

24 BOZYAZI, E.; ÜRGEN, M.; ÇAKIR, A. F. Comparison of reciprocating wear behavior of electrolytic hard chrome and arc-PVD CrN coatings. Wear, v. 256, n. 7-8, p. 832-839, 2004. 
25 ZHOU, Y. M.; ASAKI, R.; HIGASHI, K.; SOE, W. H.; YAMAMOTO, R. Sliding wear behavior of polycrystalline TiN/CrN multilayers against an alumina ball. Surf. Coat. Technol, v. 130, n. 1, p. 9-14, 2000.

26 BARSHILIA, H.; DEEPTHI, B.; SELVAKUMAR, N., JAIN, A.; RAJAM K. S. Nanolayered multilayer coatings of $\mathrm{CrN} / \mathrm{CrAIN}$ prepared by reactive DC magnetron sputtering. Applied Surface Science, v. 253, n. 11-30, p. 50765083, 2007.

27 DONG, Y.; ZHAO, W.; YUE, J.; LI, G.. Crystallization of Si3N4 layers and its influences on the microstructure and mechanical properties of ZrN/Si3N4 nanomultilayers. Appl. Phys. Lett. , p.121916-121919, n.89, 2006.

28 ROMERO, J.; ESTEVE, J.; A. LOUSA Period dependence of hardness and microstructure on nanometric $\mathrm{Cr} / \mathrm{CrN}$ multilayers. Surf. Coat. Technol, v. 188189, p. 338-343, 2004.

29 ULRICH, S.; ZIEBERT, C.; STÜBER, M.; NOLD, E.; HOLLECK, H.; GÖKEN, M.; SCHWEITZER, E.; SCHLOBMACHER, P. Correlation between constitution, properties and machining performance of $\mathrm{TiN} / \mathrm{Zr} / \mathrm{N}$ multilayers. Surf. Coat. Technol, v.188-189, p. 331-337, 2004.

30 LEE, S. Y.; KIM, G. S.; HAHN, J. H. Effect of the Cr content on the mechanical properties of nanostructured TiN/CrN coatings. Surf. Coat. Technol, v.177178, p. 426433, 2004.

31 CHANG, Y.; WANG, D.; HUNG, C. Structural and mechanical properties of nanolayered TiAIN/CrN coatings synthesized by a cathodic arc deposition process. Surf. Coat. Technol, v. 200, n. 5-6, p.1702-1708, 2005.

32 MACLAY D. Simulation Gets Into the Loop. IEEE Review, 1997. 
33 ALLES, S.; SWICK, C.; HOFFMAN, M. A Real Time Hardware in the Loop Simulation for Traction Assist. International Journal of Vehicle Design, v. 15, p. 597-625, 1994.

$34 \mathrm{KEY}, \mathrm{C}$. Cooperative Planning in the Pilot's Associate. Proc. DARPA Knowledge-Based Planning Workshop, 1987.

35 ANAKWA W, K. Environments for rapid implementation of control algorithms and hardware in the loop simulation. In IEEE 28th Annual Conference of the Industrial Electronics Society, 2002.

36 JANSSON, A.; PALMBERG, J. O. Load simulation, a flexible tool for assessing the performance of hydraulic valves. 43 th International Symposium on Fluid Control, Fluid Measurement, and Visualisation, Toulouse, France, 1994.

37 Application Note 007, Data Acquisition Fundamentals, National Instruments, 2002.

38 BISCHOP, R. H., Mechatronic System Control, Logic, and Data Acquisition, 2ed, CRC Press, 2007.

39 National Instruments, NI-USB6008, 12-Bit, 10 kS/s Low-Cost Multifunction DAQ http://sine.ni.com/nips/cds/view/p/lang/en/nid/14604.

40 National Semiconductor, LM35, Precision Centigrade Temperature Sensors, datasheet 


\section{Anexo}

O código a seguir, em linguagem de programação $C$, corresponde à biblioteca de funções essenciais para o funcionamento do algoritmo de controle.

A biblioteca é compilada para Windows, necessitando do Labwindows/CVI instalado.

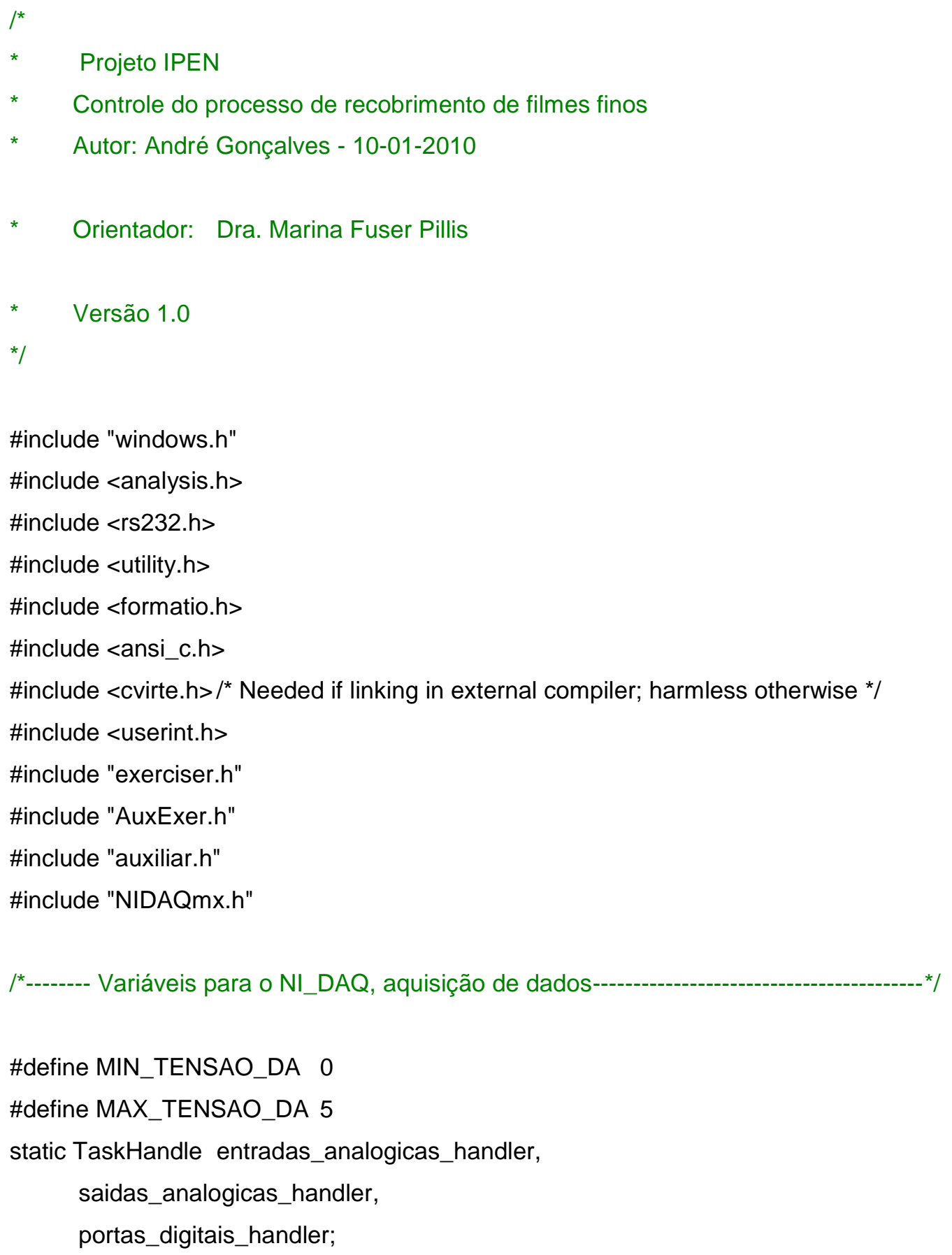

\#define MIN_TENSAO_DA 0

\#define MAX_TENSAO_DA 5

static TaskHandle entradas_analogicas_handler, saidas_analogicas_handler, portas_digitais_handler; 
// Variáveis do USB-600x

int $\quad$ status $=0$,

sampsPerChan $=256$,

tamanho $=5000$,

tamanho_real,

acao_digital;

char canal_ad_string[256] = "Dev2/ai0",

canal_da_string[256] = "Dev2/ao0:1",

canal_dig_string[256];

double rate $=10000$,

time_out $=2$,

leituras[5000],

leituras_2[1500];

int EscDigital6009(char *canal_string, ulnt32 valor_escrever, int tipo_escrita);

/*----------------- Variáveis globais ------------------------------*

long int max;

int status;

int TempNew, FinishTest, PauseTest, Ligado;

char strtemp[5] = "00", buffer [80];

static DWORD dwThreadld;

static HANDLE hThread;

extern double lim_sup, lim_inf,

Sup_Ytmhd, Sup_Serp, Sup_Princ, Sup_Prec, Sup_BpN2, Sup_BpNH3,

Inf_Ytmhd, Inf_Serp, Inf_Princ, Inf_Prec, Inf_BpN2, Inf_BpNH3;

DWORD WINAPI IPEN_Teste (LPVOID data);

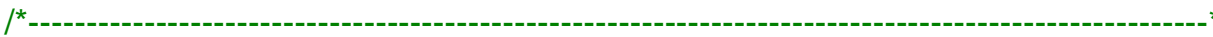

Método: main

Finalidade: Responsável por iniciar a execução do programa

Parâmetros: argumentos do sistema

Retornar:0

int main (int argc, char *argv[])

\{

int $\mathrm{i}=0$, action; 


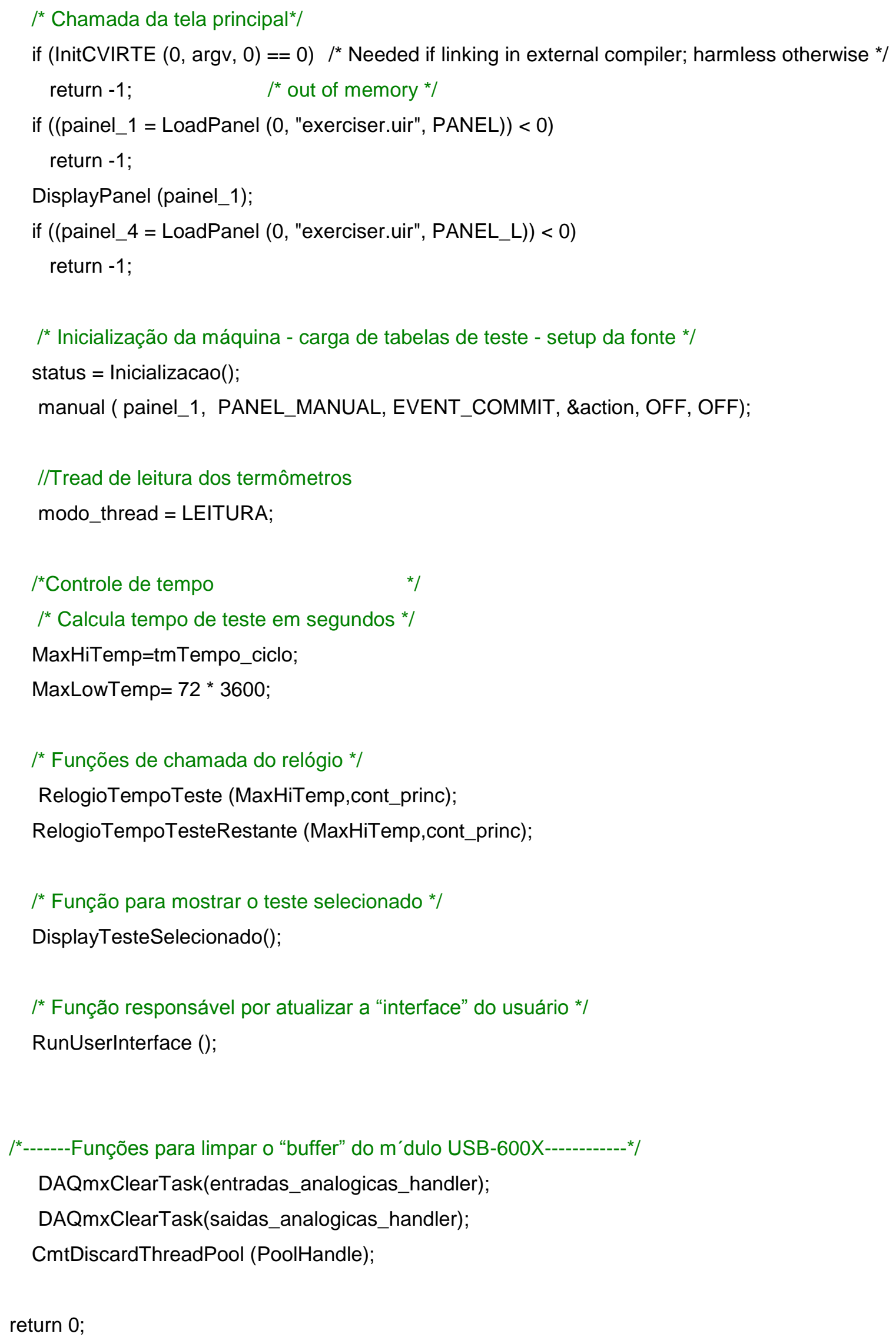




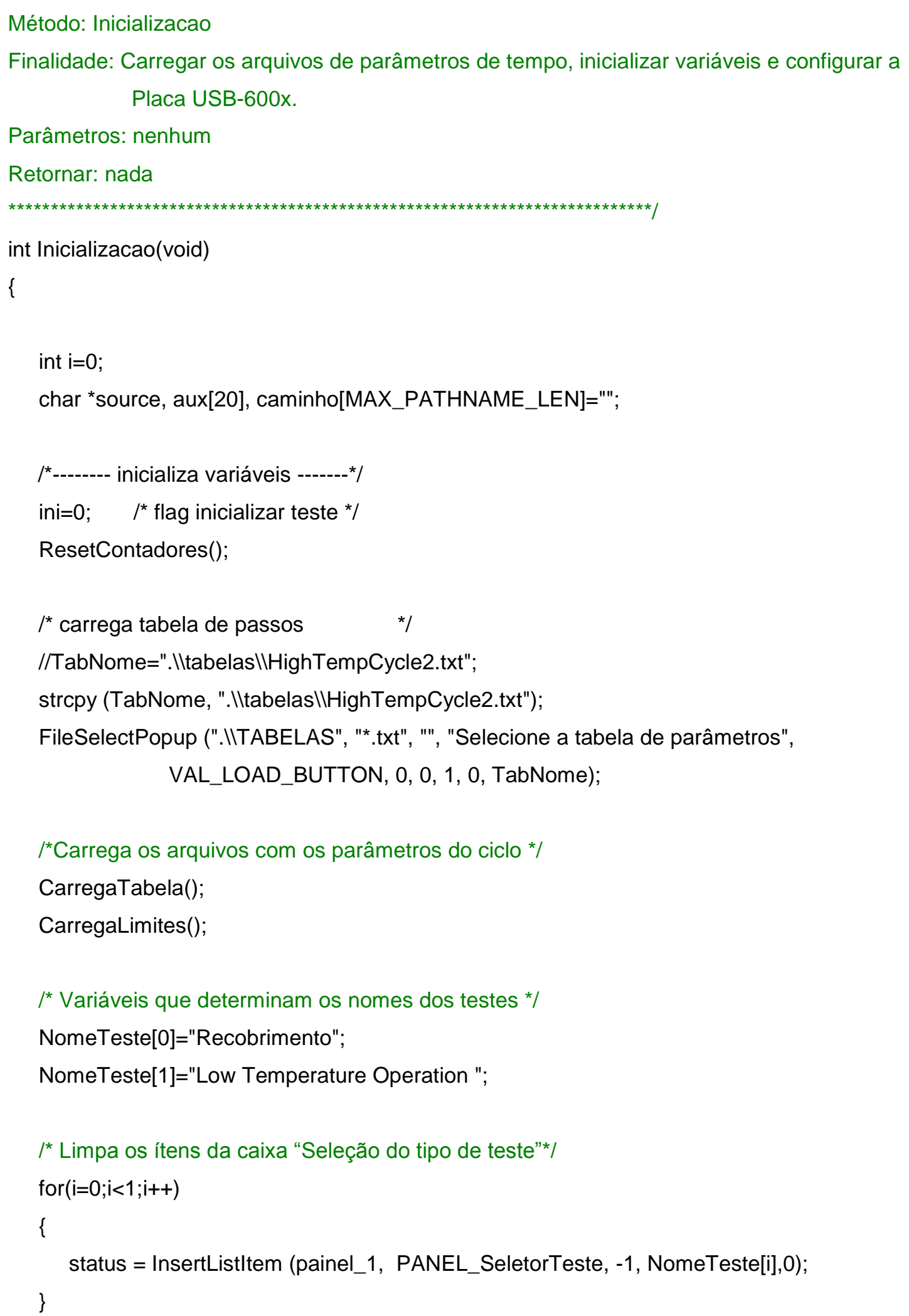


$/{ }^{*}$ Limpa a caixa de status do teste */

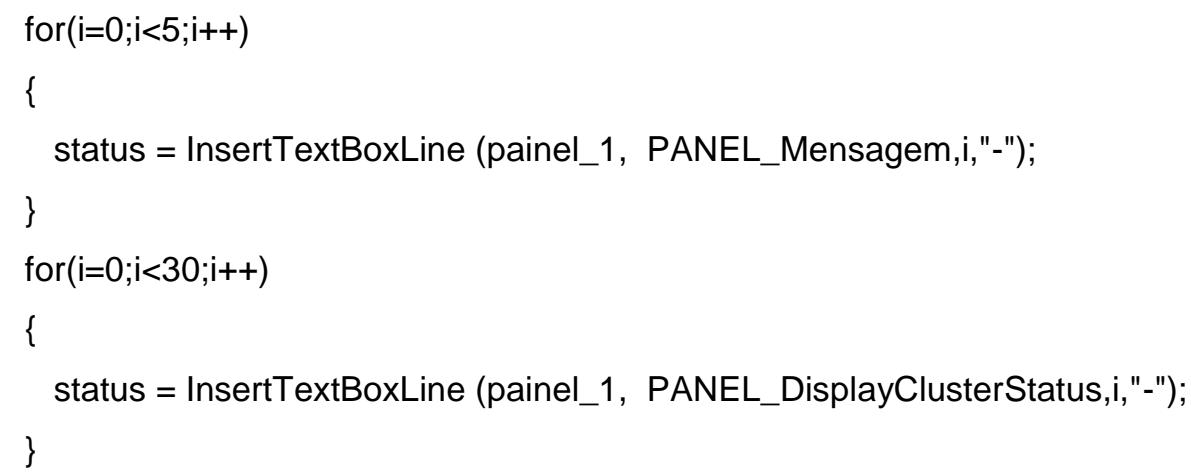




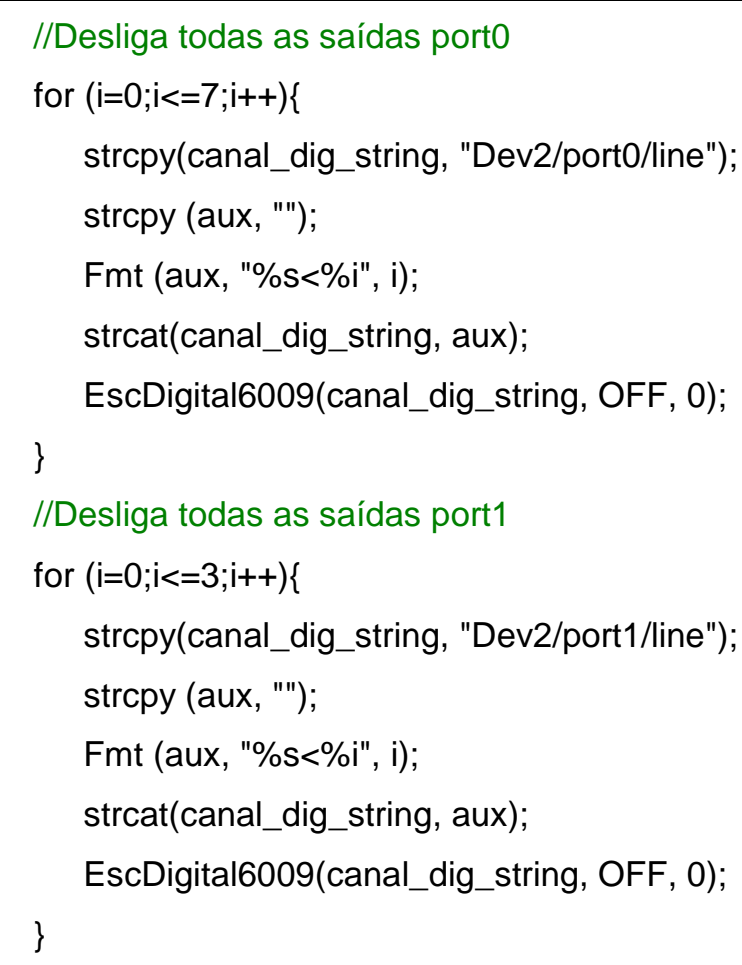

return 0;

\}

Método: Inicializacao

Finalidade: Rotina de Teste (threads), responsável pela execução da atuação das válvulas e controle do tempo do sistema -.

Parâmetros: nenhum

Retornar: nada

DWORD WINAPI IPEN_Teste (LPVOID data)

//int IPEN (void)

\{

long tpasso;

int i,rot, press $=0$, temp $=0$;

double vel,Tempo_Ligado $=$ MaxHiTemp;// ${ }^{*}$ 3600; $/{ }^{*}$ em segundos * $/$

double Tempo_Desligado $=0 ; \quad l^{*}$ em segundos (não utilizado neste teste) ${ }^{*} /$

unsigned int Numero_Ciclos $=1$;

double Tempolnicial, TempoAtual, TempoCiclo;

double TempoOff, TempoPausa $=0$,TempoPausaAnterior $=0$, ;

int ResetOffTimer = 1, status;

float Tempo_Total_Teste;

double tempo,Cycle_Number $=0$; 


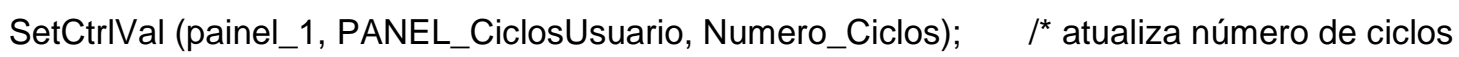
no painel */

SetCtrlVal (painel_1, PANEL_TempoLigado, (Tempo_Ligado / 60)); /* atualiza tempo ligado no painel */

SetCtrlAttribute (painel_1, PANEL_CiclosUsuario, ATTR_DIMMED, 1);

SetCtrlAttribute (painel_1, PANEL_TempoLigado, ATTR_DIMMED, 1);

Tempo_Total_Teste $=($ Tempo_Ligado + Tempo_Desligado $){ }^{*}$ Numero_Ciclos;

Tempolnicial $=$ Timer ();

do

\{

if $($ PauseTest $==1)$

\{

TempoPausaAnterior = TempoPausa;

$\mathrm{t}=$ Timer () ;

do

\{

TempoPausa $=$ Timer ()$-\mathrm{t}$;

ProcessSystemEvents();

\}

while $(($ PauseTest $==1) \& \&($ FinishTest $))$;

TempoPausa $=$ TempoPausaAnterior + TempoPausa;

\}

TempoAtual $=$ Precision $($ (Timer ()$-$ Tempolnicial $)$ - TempoPausa, 0);

if $($ ResetOffTimer $==1)$

\{

TempoOff = Timer ();

ResetOffTimer $=0$;

\}

RelogioTempoTeste (Tempo_Total_Teste, TempoAtual);

RelogioTempoTesteRestante (Tempo_Total_Teste, TempoAtual);

Scan(sTime[Passolndex],"\%s>\%i",\&tpasso);

if (Passolndex != PassolndexAntigo)

\{

modo_thread = PARAR_LEITURA;

TempoCiclo $=$ Timer () ;

DisplayPasso(Passolndex); 
RL_1(Tipln[Passolndex]);

//Delay_thread(0.05);

RL_2(TipOut[Passolndex]);

//Delay_thread(0.05);

RL_3(Reator[Passolndex]);

//Delay_thread(0.05);

RL_4(T_tmhdy_In[Passolndex]);

//Delay_thread(0.05);

RL_5(T_tmhdy_Out[Passolndex]);

//Delay_thread(0.05);

RL_6(Reator_2[Passolndex]);

//Delay_thread(0.05);

modo_thread = LEITURA;

PassolndexAntigo = Passolndex;

\}

if ( (Timer ()$-$ TempoCiclo) $>=$ tpasso )

Passolndex $=$ Passolndex +1 ;

if (Tempo_Desligado !=0 )

\{

if $(($ Timer ()$-$ TempoOff $)>=$ (Tempo_Ligado $)$ )

\{

ResetOffTimer $=1$;

tempo $=$ Timer () ;

do

\{

///Delay_thread(1);

if $($ PauseTest $==1)$

\{

TempoPausaAnterior = TempoPausa;

$\mathrm{t}=$ Timer ();

do

\{

TempoPausa $=$ Timer ()$-\mathrm{t}$;

ProcessSystemEvents();

\}

while ( (PauseTest $==1)$ \& \& (!FinishTest) );

TempoPausa $=$ TempoPausaAnterior + TempoPausa; 


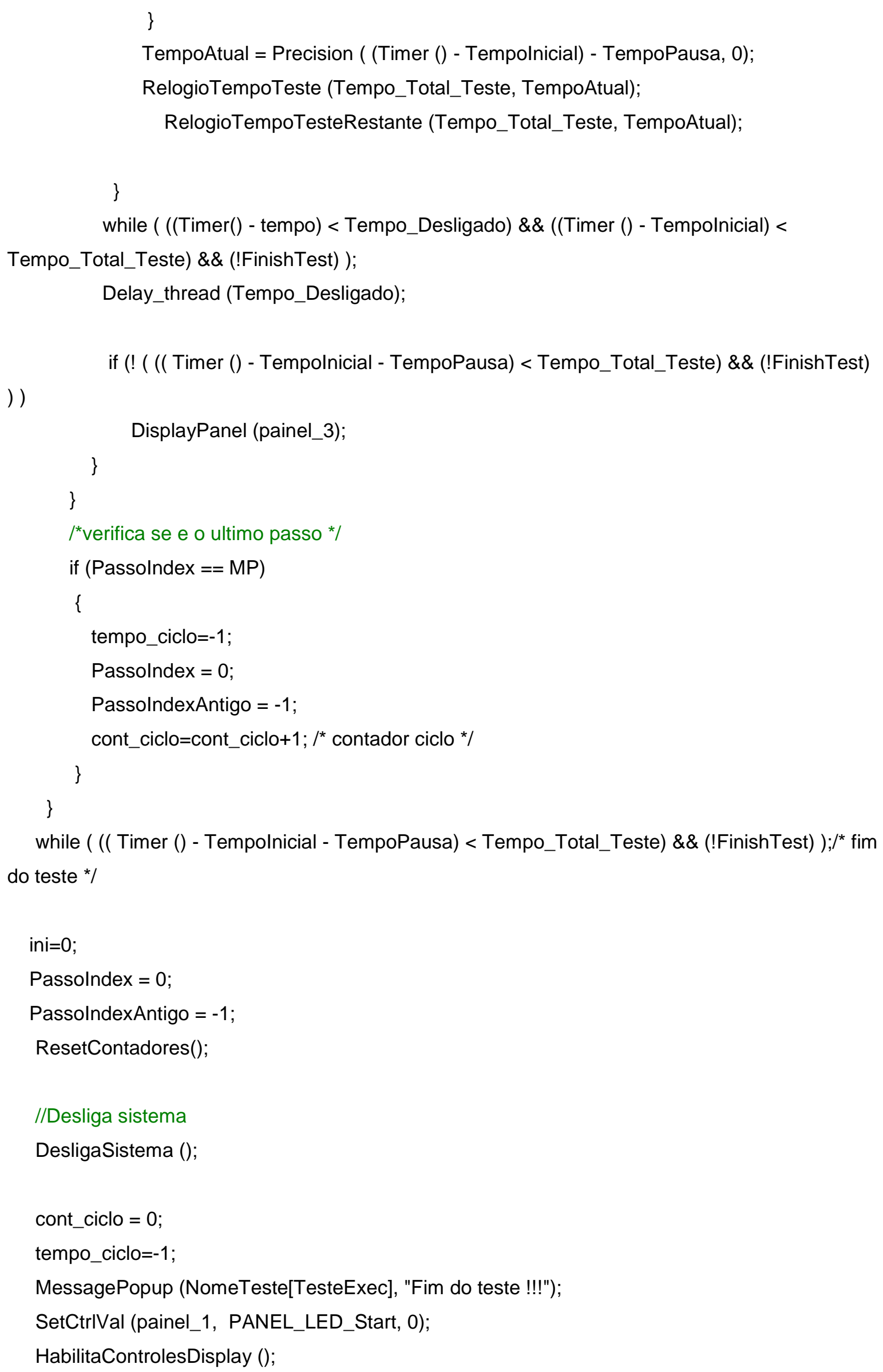


SetCtrlAttribute (painel_1, PANEL_CiclosUsuario, ATTR_DIMMED, 0);

SetCtrlAttribute (painel_1, PANEL_TempoLigado, ATTR_DIMMED, 0);

return 0;

\}

Método: RL_1

Finalidade: Rotina interna de acionamento dos reles

Parâmetros: nome do botão

Retornar: nada

void RL_1(char *st)

\{

int result;

strcpy (canal_dig_string, nDev);

strcat(canal_dig_string, "/port0/line0");

result $=$ CompareStrings (st, 0, "on", 0, 0);

if $($ result $==0)\{$

SetCtrlAttribute (painel_1, PANEL_RL_1, ATTR_CTRL_VAL, ON);

SetCtrlVal (painel_1,PANEL_LED_2,ON);

EscDigital6009(canal_dig_string, ON, 0);

\}

result $=$ CompareStrings (st, 0 , "off", 0,0$)$;

if $($ result $==0)\{$

SetCtrlAttribute (painel_1, PANEL_RL_1, ATTR_CTRL_VAL, OFF);

SetCtrIVal (painel_1,PANEL_LED_2,OFF);

EscDigital6009(canal_dig_string, OFF, 0);

\}

\} 